\section{POSTER PRESENTATION ABSTRACTS}

\section{P-001 \\ EVALUATION OF TURNAROUND TIME PERFORMANCES OF} BLOOD GAS TESTS

Aysegul Buyukbebeci, Mehmet Akif Bozdayi, Mehmet Tarakcioglu Department of Medical Biochemistry, Gaziantep University, Gaziantep, Turkey

BACKGROUND AND AIM: The turnaround time is considered as one of the most important quality indicators in the evaluation of laboratory performance for the laboratory services offered. The International Standards Organization (ISO) 15189 has set requirements for timely test results.Our clinical biochemistry laboratory, accredited with ISO 15189, performs turnaround time performance analysis periodically.In this study, it is aimed to analyze the turnaround time performance of the blood gas test of our laboratory between June 1, 2020 and June 1,2021 and to determine the corrective and preventive actions to be taken. METHODS: The turnaround time for blood gas tests admitted to our Clinical Biochemistry Laboratory from the emergency department between June 1, 2020 and June 1, 2021 were evaluated.Turnaround time was defined as the time elapsed between the acceptance of the samples to the laboratory and the approval of the test results. The data were obtained retrospectively from the Laboratory Information Management System.Targeted laboratory result time was 20 minutes for blood gas test. The target value in turnaround time performance was determined as $85 \%$ and above.

RESULTS: Between 1 June 2020 and 1 June 2021, from emergency department, a total of 18,858 tests were accepted and reported in our laboratory.Laboratory turnaround times within the time specified in the blood gas tests were $95.14 \%$ (mean 9 minutes), respectively.

CONCLUSIONS: The turnaround times for blood gas tests are within target values.It is aimed to reduce the current turnaround times in order to increase the laboratory service performance.In this context, corrective and preventive activities and personnel trainings are planned in the laboratory.

Keywords: Turnaround Time, Quality Indicators, Total Testing Process.

\section{P-002 \\ EVALUATION OF THE TOTAL ALLOWABLE ERRORS OF ROUTINE BIOCHEMISTRY TESTS}

Omer Burak Taskaya, Havva Yasemin Cinpolat, Dilek Ulker Cakir, Damla Torun

Department of Medical Biochemistry, Canakkale 18 Mart University, Faculty of Medicine, Canakkale, Turkey

BACKGROUND AND AIM: In this study, we aimed to calculate the total error values of routine biochemistry tests and to evaluate them within the framework of the national criteria determined by the Ministry of Health and Clinical Laboratory Improvement Amendments (CLIA).

METHODS: Total error was calculated for albumin, alanine aminotransferase (ALT), aspartate aminotransferase (AST), alkaline phosphatase (ALP), chloride, total cholesterol (TC), glucose, high-density lipoprotein (HDL), lactate dehydrogenase (LDH), potassium, total protein, sodium, triglyceride and urea tests. All these test studied in Cobas 8000, Cobas 6000-1 and Cobas 6000-2 (Roche Diagnostics, Mannheim, Germany) analyzers used in our laboratory. Bias(\%) was obtained from external quality control (RIQAS, Randox international quality assessment scheme) data and coefficient of variation (CV) was obtained from internal quality control data studied for 20 consecutive days with 2 levels. Bias (\%) was calculated with the formula [ (average value-average peer value)/average peer value ${ }^{*} 100 ; \mathrm{CV}$ was calculated with the formula [(SD/ Mean value) $]^{*} 100$. The formula $\mathrm{TE}=\mathrm{Bias}(\%)+1,65 * \mathrm{CV}$ was used.

RESULTS: When the calculated total error were compared with the national criteria, it was found within the determined limits for all three analyzers. In comparison with CLIA criteria, albumin and sodium in cobas 6000-1 analyzer; sodium and urea in the cobas 6000-2; in the cobas 8000 analyzer, albumin, chloride, TC, LDH and sodium tests were found above the allowable TE values. CONCLUSIONS: Although the criteria determined by the Turkish Ministry of Health in terms of ease of use in laboratory are more appropriate, since the CLIA criteria are within narrower limits, it is thought that it will be beneficial in the early detection and intervention of errors.

Keywords: Quality management system, total allowable error, analytical performance

\section{P-003 \\ COMPARISON OF LC-MS AND ROUTINE SPECTROPHOTOMETRIC CREATININE MEASUREMENT METHODS AND EVALUATION OF THE EFFECTS ON EGFR CALCULATION}

\author{
Cemil Nural ${ }^{1}$, Fatma Meric Yilmaz ${ }^{2}$, Gulsen Yilmaz ${ }^{3}$ \\ ${ }^{1}$ Ankara Pursaklar State Hospital, Medical Biochemistry Laboratory, Ankara, \\ Turkey \\ ${ }^{2}$ Ankara City Hospital, Central Biochemistry Laboratory, Ankara, Turkey \\ ${ }^{3}$ Ankara Yildirim Beyazit University, Faculty of Medicine, Department of \\ Biochemistry, Ankara, Turkey
}

BACKGROUND AND AIM: Creatinine levels are important to detect and monitor kidney function thus they should be analyzed with high sensitivity. Therefore, creatinine is a commonly used clinical parameter, yet research on the accuracy of the measurement method remains currently. Limitations in accuracy and precision in creatinine measurement have led to the search for new biomarkers as cystatin C, Beta Trace Protein (BTP) and Symmetric-Dimethyl Arginine (SDMA), as an renal marker as an alternative to creatinine.

METHODS: In our study, we determined liquid-chromatography mass spectrometry (LC-MS / MS) measurement method as the reference method for creatinine quantification. After the LC-MS MS creatinine method validation studies performed according to CLSI protocols and studies in the literature, we also compared the results of Jaffe method and enzymatic method with LC-MS/ MS creatinine results. We investigated correlation cystatin C, BTP and SDMA levels as an alternative marker with LC MS / MS creatinine measurement method that reference method. We examined the effect of the obtained results on CKD-EPI eGFR calculation. Siemens commercial kit and ADVIA 1800 device were used for routine creatinine analysis, Siemens commercial kit suitable for nephelometric device was used for BTP and Sistain C, and LC-MS/MS was used for SDMA analyzes.

RESULTS: At the comparison results, there was a strong correlation between Jaffe Method and enzymatic creatinine method and was obtained consistent results in regression analysis ( $\mathrm{r} 2=0.96-0.97)$. The LOD (Limit of Detection) and LOQ (Limit of Quantitation) results of the validated LC-MS/MS method were obtained as $0.01 \mathrm{mg} / \mathrm{dL}$ and $0.04 \mathrm{mg} / \mathrm{dL}$, respectively. GFR values calculated with the combination of cystatin $\mathrm{C}$ and cystatin $\mathrm{C}+$ creatinine showed a strong correlation with the eGFR values obtained according to LC-MS/MS creatinine data $(\mathrm{r} 2=0.92$ ve $0.95 ; \mathrm{p}<0.05)$.

CONCLUSIONS: It is recommended that the methods of the tests, which are important for clinical decision, to be standardized between the laboratories by standard reference materials (SRM) or a reference method. According to all our results, especially LOD and LOQ, we think that our LC-MS/MS method can be suitable for creatinine measurements in pediatric and geriatric patient populations that a sensitive measurement method is needed, with low creatinine levels. Keywords: Creatinine, GFR, LC-MS/MS, Jaffe method, Cystatin C.

\section{P-004}

\section{EVALUATION OF IMPRECISION AND REFERENCE CHANGE}

\section{VALUE OF TUMOR MARKERS ON ROCHE COBAS 8000 ANALYZER}

Fatih Serin, Yunus Emre Haskilic, Gizem Yilmaz Calik, Semih Fazli Kayahan, Hacer Dogan, Mehmet Senes

Department of Medical Biochemistry, Ankara Training and Research Hospital, Ankara, Turkey

BACKGROUND AND AIM: The population-based reference range is the basis for interpreting test results when an individual previous data are not available. However, changes in the individual's serial measurements may be related to the status of the disease as well as being affected by analytical and intra-individual variation. The reference change value (RCV) expresses the clinical significance of the change between two consecutive test results, especially in tests with a low individuality index, laboratory test results exceeding this value are associated with the individual's disease state. In this study, we aimed to calculate our RCV for eight tumor markers (AFP, CA15-3, CA19-9, CA125, CEA, f-PSA, t-PSA and calcitonin) to improve clinical use in our hospital.

METHODS: Six-month internal quality control results for serum analytes of AFP, CA15-3, CA19-9, CA125, CEA, f-PSA, t-PSA and calcitonin studied on Cobas 8000 immunochemistry analyzer with Roche reagents in our laboratory were used to calculate the analytical coefficient of variation (CVA). Intraindividual coefficients of variation (CVI) were obtained from median values from meta-analysis studies in the EFLM database of biological variation. RDD was calculated with the formula $\mathrm{Z} \times 2^{1 / 2} \times\left(\mathrm{CVA}^{2} \times \mathrm{CVI}^{2}\right)^{1 / 2} .(Z=1.96,95 \%$ probability, bidirectional; $Z=2.58,99 \%$ probability, bidirectional; $Z=1.65,95 \%$ probability, unidirectional; $Z=2.33,99 \%$ probability, unidirectional)

RESULTS: Analytical coefficients of variation (CVA) were found to be $5.81 \%$ for AFP, $3.25 \%$ for CA $15-3,3.74 \%$ for CA $19-9,4.82 \%$ for CA $125,3.78 \%$ for CEA, $4.77 \%$ for f-PSA, $3.13 \%$ for t-PSA and $6.03 \%$ for calcitonin. Calculated RCV ( $\mathrm{Z}=1.96,95 \%$ probability, bidirectional) was found to be $75.7 \%$ for AFP, $15 \%$ for CA $15-3,63.2 \%$ for CA $19-9,39.2 \%$ for CA $125,50.7 \%$ for CEA, $23.7 \%$ for f-PSA, $20.8 \%$ for t-PSA and $39.7 \%$ for calcitonin.

CONCLUSIONS: It is important for laboratories to consider analytical and biological sources of variation in order to obtain reliable results. For the change in an individual's serial measurement results to be clinically significant, the change 
must be greater than the total variation inherent in the results being compared. Reporting RCV alongside the population-based reference range can be used as a valuable tool in clinical judgment, especially in patients with follow-up. Keywords: reference change value, imprecision, biological variation, tumor markers

\section{P-005 \\ EVALUATION OF THE CORRELATION BETWEEN ERYTHROCYTE SEDIMENTATION RATE AND HEMATOCRIT-CORRECTED ERYTHROCYTE SEDIMENTATION RATE WITH C-REACTIVE PROTEIN}

Ayse Ulusoy, Neslihan Sungur, Didem Barlak Keti, Sabahattin Muhtaroglu Department of Medical Biochemistry, Erciyes University, Kayseri, Turkey

BACKGROUND AND AIM: Erythrocyte sedimentation rate (ESR) and C-reactive protein (CRP); are two commonly requested laboratory tests that can help accurately diagnose and monitor inflammatory conditions such as infection, trauma, infarction, neoplasm, inflammatory arthritis, and systemic autoimmune disease. The aim of this study is to evaluate the correlation between normal ESR values and hematocrit-corrected ESR values at different ESR ranges with CRP. METHODS: A total of 100 patients with 20 patients in each group, whose ESR values were $0-20 \mathrm{~mm} / \mathrm{h}, 20-40 \mathrm{~mm} / \mathrm{h}, 40-60 \mathrm{~mm} / \mathrm{h}, 60-80 \mathrm{~mm} / \mathrm{h}$, and over $80 \mathrm{~mm} / \mathrm{h}$, measured with the Vision c automatic ESR system, were determined. The hematocrit of these patient groups was analyzed Sysmex XN-1000 and the CRP value was analyzed on Roche Cobas ${ }^{\circledR} 8000$. ESR values corrected for hematocrit were calculated according to the formula [(hematocrit/45)Xsedimentation]. The correlation of these values with CRP and their clinical significance were examined.

RESULTS: Measured ESR values and hematocrit corrected ESR values made a statistically significant difference $(\mathrm{p}<0.001)$, but the clinical significance calculated according to Cohen's d coefficient did not costitute a difference in the range of $0-20 \mathrm{~mm} / \mathrm{h}$. These two compared ESR values were not correlated with CRP in all ESR intervals $(p>0.05)$. There was correlation between corrected ESR and hematocrit except the $0-20 \mathrm{~mm} / \mathrm{hr}$ ESR range $(\mathrm{p}<0.05)$.

CONCLUSIONS: Since ESR is a test performed on whole blood, it is anticipated that it may be affected by blood compositions. It is known that it can be affected especially by hematocrit values. In this study, it was observed that the hematocrit values was significantly low in sedimentation values measured at $80 \mathrm{~mm} / \mathrm{h}$ and above. Therefore, it was understood that a correction should be made in this range. In addition, the lack of correlation with CRP in different sediment ranges in this study, but the fact that there was a numerical correlation was attributed to the insufficient number of samples.

Keywords: Erythrocyte sedimentation rate, hematocrit, C-reactive protein

\section{P-006 \\ CALCULATION OF MEASUREMENT UNCERTAINTY OF VITAMIN \\ B12}

Caner Yildiz, Tugce Yildiz, Omer Faruk Ozer

Department of Clinical Biochemistry, Bezmialem Foundation University,

Istanbul, Turkey

BACKGROUND AND AIM: Measurement uncertainty is an important parameter in clinical biochemistry. Calculation of measurement uncertainty helps clinicians, especially when the smallest change in parameter level affects the outcome. The aim of this study was to calculate the measurement uncertainty of vitamin B12 results measured in Bezmialem Foundation University biochemistry laboratory and to compare the result with total allowable error $\%(\mathrm{TEa} \%)$.

METHODS: Vitamin B12 was analyzed by Abbott Architect i2000SR using Abbott Architect B12 kit, which is a chemiluminescent microparticle intrinsic factor assay kit. The measurement uncertainty calculation model explained in Nordtest guide was used. Internal quality control data was taken from Abbott Architect i2000SR. RIQAS external quality reports were used to calculate $u$ (bias) value.

RESULTS: The \%CVs of vitamin B12 internal quality controls (level 1-2-3) were found to be $8.84,5.59$, and 6.59 , respectively. uRw value was calculated as $3.57 \%$, and $\mathrm{u}$ (bias) was $7.3 \%$. Uc result was $8.11 \%$, and the measurement uncertainty value for vitamin B12 was calculated as $16.23 \%$. This value was under the target value set by CLIA, which is $25 \%$ for vitamin B12.

CONCLUSIONS: It is impossible to analyze any sample and find the exact amount of the desired analyte with our current equipment. Every calculation in clinical laboratories has some amount of uncertainty, i.e. measurement uncertainty. It is important to calculate the measurement uncertainty of the desired parameter to see if the result is above $\mathrm{TEa} \%$. In conclusion, we showed in our study that vitamin B12 results measured in Bezmialem Foundation University biochemistry laboratory had a measurement uncertainty of $16.23 \%$, which was below the TEa set by CLIA.

Keywords: Measurement Uncertainty, Vitamin B12, CLIA

\section{P-007 \\ CALCULATION OF REFERENCE CHANGE VALUES OF THE D-DIMER TEST}

Hacer Dogan, Kezban Cavdar Yetkin, Fatih Serin, Semih Fazli Kayahan, Mehmet Senes, Ilknur Alkan

Department of Medical Biochemistry, Ankara Training and Research Hospital, Ankara, Turkey

BACKGROUND AND AIM: D-dimer is considered a reliable marker of both coagulation activation and fibrinolysis. However, data on the biological variation of D-dimer are still limited. The numerical value that indicates the clinical significance of the change between two consecutive results is known as the critical difference or reference change value (RCV). Biological variation data has many important applications in laboratory medicine. In this study, we aimed to calculate our RCV in order to improve the clinical use of D-dimer in our hospital. METHODS: The analytical coefficient of variation (CVA) was calculated from the 2 month two-level results of the internal quality controls that we ran twice a day for D-dimer on a Roche Cobas 6000 analyzer in our laboratory. Intraindividual coefficients of variation (CVw) were obtained from the WESTGARD database of biological variation. RCV was calculated with the formula Z x $21 / 2 \mathrm{x}$ (CVA2 x CVW2) $1 / 2$ (95\% CI, Z=1.96).

RESULTS: Individuality index and reference change value for $D$-dimer $(Z=1.96$, $95 \%$ probability, bidirectional) were calculated as $0.87 \%$ and $65 \%$, respectively. CONCLUSIONS: Analytical and biological variation calculations are taken into account when assessing the clinical significance of the variation between two consecutive outcomes of an individual. In tests with an individuality index $<1$, it is considered significant to exceed the RCV even if the results are within the reference range. The use of $\mathrm{RCV}$ in addition to the reference range for many analytes in the laboratory both improves decision making in a clinical setting and provides more reliable results from laboratories.

Keywords: D-dimer, Internal Quality Control, Reference Change Value

\section{P-008 \\ EVALUATION OF AUTOVERIFICATION SYSTEM PERFORMANCE USED FOR COMPLETE BLOOD COUNT IN OUR LABORATORY}

Yunus Emre Haskilic ${ }^{1}$, Semih Fazli Kayahan ${ }^{1}$, Ilknur Alkan Kusabbi ${ }^{1}$, Mehmet Senes ${ }^{1}$, Dogan Yucel ${ }^{2}$

${ }^{1}$ Ankara Training and Research Hospital, Medical Biochemistry, Ankara, Turkey ${ }^{2}$ Lokman Hekim University, Medical Biochemistry, Ankara, Turkey

BACKGROUND AND AIM: Aim of this study is to evaluate performance of autoverification procedure carried out with the Sysmex Extended IPU program for routine complete blood count $(\mathrm{CBC})$ results.

METHODS: The study was carried out with the routine $\mathrm{CBC}$ results of the patients who applied to the outpatient clinics of our hospital. Routine CBC results analyzed between 01.06.2021-31.08.2021 were evaluated. Analyzes were performed on Sysmex XN-2000 and XN-3000 analyzers. Autoverification rules were defined to Extended IPU program. Critical value and Delta check rules were defined for hemoglobin, platelet and leukocyte results. Critical values $<6$ and $>20$ $\mathrm{g} / \mathrm{dL}$ for hemoglobin, $<150$ and $>1000$ 103/UL for platelet, $<2$ and $>30103 / \mathrm{UL}$ for leukocyte. Delta check rules \%25/90 days for hemoglobin, $\% 50 / 90$ days for platelet and \%50/90 days for leukocyte were defined. In addition, in the presence of the abnormal WBC scattergram warning and lipemia/hemolysis/agglutinine suspect, the autoverification was blocked.

RESULTS: The number of routine complete blood count results studied in the 3 -month period is 41,973 . 40,792 test results $(97.18 \%)$ were autoverified. On the other hand, 1181 samples $(2.82 \%)$ were manually verified. The most common reason for manual verification was the platelet critical value (684 samples-\%1.63). This number was $259(0.62 \%)$ for abnormal WBC Scattergram alarm, $59(0.14 \%)$ for Platelet Delta Check, $50(0.12 \%)$ for the suspicion of lipemia/hemolysis/agglutinine, $47(0.11 \%)$ for WBC Delta check, $47(0.11 \%)$ for hemoglobin critical value, $31(0.08 \%)$ for WBC critical value, $4(0.01 \%)$ for hemoglobin delta check.

CONCLUSIONS: Autoverification ratio is well in terms of the reduction of laboratory workload and shortening of turnaround time. The most common cause of manual verification is platelet critical value. This situation is generally resulted from the clotted sample. The clotted sample, which is the most common source of preanalytical error in hematology laboratories, can be easily detected by autoverification system.

Keywords: Autoverification System, Complete Blood Count, Preanalitic Error 


\section{P-009}

\section{IMPORTANCE OF CXADR GENE IN COVID-19}

Fatih Hacimustafaoglu ${ }^{1}$, Ersin Ibisoglu², Duygu Kirkik

${ }^{1}$ University of Health Sciences, Department of Medical Biochemistry, Istanbul, Turkey

${ }^{2}$ Basaksehir Cam and Sakura City Hospital, Department of Cardiology, Istanbul, Turkey

${ }^{3}$ University of Health Sciences, Department of Medical Biology, Istanbul,

Turkey

BACKGROUND AND AIM: The symptoms of coronavirus and myocarditis are similar to each other, such as chest pain. It is very important to distinguish between these two diseases to prevent or treat the disease. In this study, we aimed to describe connection of CXADR gene and ACE2 in COVID-19.

METHODS: We were found similar genes with CXADR gene and ACE2 using STRING and GENEMANIA databases. Then, we attained pathway of viral myocarditis using KEGG Pathway Databases. After that, we got probably damaging SNPs on CXADR gene using Exome Variant Server and Polyphen2 databases.

RESULTS: First of all, we showed the viral myocarditis pathway in our study. We found the expression level of the CXADR gene using bioinformatics methods and our results showed that the CXADR gene is overexpressed in skin, bladder, brain, stomach, prostate and testis. Then, we found 78 variations in the CDXADR gene in European American and African American populations, 11 of them were damaging polymorphisms in the CXADR gene.

CONCLUSIONS: Our results may be support to explain the pathogenesis of high-risk group diseases in COVID-19. In the future, this study may contribution to solve physiopathology of COVID-19 linked with myocarditis.

Keywords: Cardiovascular diseases, infectious diseases, inflammatory diseases, viral infections

\section{P-010 \\ INVESTIGATION OF GUT MICROBIOME IN HEALTHY INDIVIDUALS BY 16S METABARCODING METHOD}

Hazal Tahravi ${ }^{1}$, Beril Erdem Tuncdemir ${ }^{1}$, Huseyin Ozgur Ozdemirel ${ }^{1}$, Eyup Hakan Alan', Saadet Alan ${ }^{3}$, Sibel Kucukyildirim ${ }^{1}$, Hatice Mergen ${ }^{1}$, Ceren Acar ${ }^{4}$

${ }^{1}$ Hacettepe University, Faculty of Science, Departmant of Biology, Molecular Biology Section, Ankara, Turkey

${ }^{2}$ Malatya Training and Research Hospital, Gastroenterology Section, Malatya, Turkey

${ }^{3}$ Inonu University, Faculty of Medicine, Departmant of Medical pathology,

Malatya, Turkey

${ }^{4}$ Inonu University, Faculty of Arts and Science, Departmant of Molecular Biology an Genetics, Malatya, Turkey

BACKGROUND AND AIM: Gut microbiota may have important effects on human health, such as nutrition, immunity, chronic diseases, and behavior: thus its disruption may result in developing many pathological conditions (e.g. Celiac disease, gastroenteritis, inflammatory bowel disease). For this reason, the reliable identification of members of the human healthy gut microbiota can be a guide to develop effective treatment regimes for microbiota-related diseases. This study aimed to determine the members of healthy gut microbiota.

METHODS: Nine healthy gut tissues were collected from volunteers during a routine colonoscopy. DNA extractions were performed using TRIzol reagent and then, quantity and quality of the DNA samples were controlled. Bacterial 16s rRNA variable region (V3-V4) was sequenced by using Illumina Miseq platform. Bioinformatic analysis of the raw data was carried out using QIIME2 and taxonomic assignments were done by using SILVA database with a 70\% confidence level cutoff for assignment. This work was supported by the grant from Inonu University Research Fund (FCD-2020-2065)

RESULTS: A minimum of 40.000 high-quality paired-end reads per sample were provided by $16 \mathrm{~S}$ rDNA targeted sequencing. Across all samples, the most abundant Bacterial phylum was Firmicutes. Although our analysis found that the most abundant bacterial genus was Bacteriodes, the most abundant species were Faecealibacterium prausnitzii, Prevotella copri and Bacterioides vulgatus. These species have previously reported as the members of healthy gut microbiota and may have potentially important roles in promoting gut health.

CONCLUSIONS: This work will contribute to our understanding of the microbial community structure and composition of the healthy gut. However, further surveys will improve our knowledge of gut microbiota in health and disease.

Keywords: Microbiota, metagenomics, 16s rRNA

\section{P-011 \\ THE ROLE OF MCV IN THE RATIONAL TEST REQUEST OF VITAMIN B12}

Kezban Cavdar Yetkin ${ }^{1}$, Gizem Yilmaz Calik ${ }^{1}$, Pinar Yilmaz ${ }^{2}$, Hacer Dogan ${ }^{1}$ Fatih Serin ${ }^{1}$, Mehmet Senes ${ }^{1}$

'Ankara Training and Research Hospital, Department of Medical Biochemistry, Ankara, Turkey

${ }^{2}$ Sisli Hamidiye Etfal Training and Research Hospital, Department of Medical Biochemistry, Istanbul

BACKGROUND AND AIM: The aim of this study is ensure the correct use of laboratory resources by analyzing the relationship between Vitamin B12 and $\mathrm{MCV}($ Mean Corpuscular Volume).

METHODS: In this study, Vit B12 and MCV levels of patients who applied to Ankara Training and Research Hospital outpatient clinics between February 1 and August 1,2021 were analyzed retrospectively. VitB12 and MCV results of a total of 49517 patients, 15222 males and 34295 females were evaluated. Patients with MCV results $<80 \mathrm{fL}$ were classified as microcytic, those with $80-100 \mathrm{fL}$ as normocytic, and $>100 \mathrm{fL}$ as macrocytic. The cut-off value for vitamin B12 deficiency was $<200 \mathrm{ng} / \mathrm{L}$. VitB12 was measured by the electrochemiluminescent method in Roche Cobas 8000 and MCV was measured in Sysmex XN3000 complete blood count analyzer. Statistical analyzes were performed with the SPSS Ver 24 package program.

RESULTS: MCV was normocytic and microcytic in 49224 patients (99.4\%), and MCV was macrocytic in 293 patients $(0.59 \%)$. MCV was macrocytic in only 4 $(2 \%)$ of 202 patients $(0.41 \%)$ with vitB $12<200 \mathrm{ng} / \mathrm{L}$. The number of patients with normal and low MCV levels and with VitB12 deficiency were $188(0.4 \%)$. No significant correlation was found between Vit B12 and MCV levels in patients with vitamin B12 deficiency $(r=0.006, p>0.05)$. There was no significant difference in VitB12 levels in grouping as microcytic, normocytic and macrocytic $(\mathrm{p}>0.05)$

CONCLUSIONS: Although a protocol is required to avoid unnecessary use of laboratory resources; the uncertainty of compatibility between VitB12 and MCV makes it difficult to establish a protocol. However, it is appropriate to consider existing guidelines to avoid unnecessary testing, especially for Vitamin B12. Keywords: MCV, Rational Test Request, Vitamin B12

\section{P-012}

SERUM ANTIMULLERIAN HORMONE LEVELS AND COMPATIBILITY WITH TESTOSTERONE IN CHILDHOOD PERIOD

Nigar Abdulazade, Gunnur Dikmen, Asli Pinar, Oytun Portakal Hacettepe University Faculty of Medicine, Department of Medical Biochemistry, Ankara, Turkey

BACKGROUND AND AIM: Antimullerian Hormone (AMH) measurement is important in the diagnosis and follow-up of childhood reproductive-disorders. The aim was to determine the reference-ranges of AMH for the Beckman-CoulterDXI800 measurement based on age for boys and girls by indirect method, and also its compatibility with serum-testosterone.

METHODS: Study population consisted of children aged 0-18 years, who applied to Children's Hospital between 2015-2021, and whose AMH and sex-steroids were measured. Children with reproductive/endocrine disorders were excluded. Serum AMH was measured by the two-step sandwich method using BeckmanCoulter DXI800. A 2.5 percent and 97.5 percent were detected with $95 \%$ CI. Serum testosterone was determined by the CMIA method (Abbott Diagnostics, IL,USA).

RESULTS: A classification was made based on age for boys and girls: Of 1111 patients 758 were girls/ 353 were boys. Groups of $0-1$ mo, 1mo-1y, 1-3y, 3-6y, $6-12 \mathrm{y}, 12-18 \mathrm{y}$ were formed. A reference range was determined for the AMH of this papulation. AMH peaked between $1 \mathrm{mo}-3$ y of age in boys $(<224 \mathrm{ng} / \mathrm{mL})$; it started to decrease in prepubertal-period $(<88 \mathrm{ng} / \mathrm{mL})$; remained at a low level $(<25 \mathrm{ng} / \mathrm{mL})$ in pubertal-period. AMH levels in girls were lowest in neonatalperiod $(<0.7 \mathrm{ng} / \mathrm{mL})$; it started to rise in prepubertal-period $(<6.8 \mathrm{ng} / \mathrm{mL})$; did not change in pubertal-period $(<9.4 \mathrm{ng} / \mathrm{mL})$. Serum testosterone increased in the prepubertal and pubertal periods in boys and girls.

CONCLUSIONS: In this study, AMH reference ranges were determined for Beckman Coulter DXI800 for girls and boys in the childhood. In boys, AMH was more compatible with testosterone in the first month.

Keywords: Anti mullerian hormone, reference range, Beckman DXI800, testosterone 
P-013

DEVELOPMENT AND COMPARISON OF DERIVATIZED AND

DIRECT LC-MS/MS METHODS FOR MEASUREMENT OF ARGININE, HOMOARGININE, ORNITHINE, CITRULLINE, ARGININOSUCCINATE, ADMA AND SDMA IN DIALYSIS PATIENTS

Murat Celik ${ }^{1}$, Emine Karakus ${ }^{2}$

${ }^{1}$ Department of Chemistry, Yildiz Technical University, Istanbul; BOME Trivitron, Ankara, Turkey

${ }^{2}$ Department of Chemistry, Yildiz Technical University, Istanbul, Turkey

BACKGROUND AND AIM: A non-derivative, easy, simple and economical LC-MS/MS method was developed for simultaneous measurement of Arginine (Arg), N-methylarginine (L-NMA), Asymmetric Dimethylarginine (ADMA) and Symmetrical Dimethylarginine (SDMA) which are molecules involved in Arginine and Nitric oxide metabolism as well as their precursor molecules including Homoarginine (HArg), Ornithine (Orn), Citrulline (Cit), Homocitrulline (HCit), Argininosuccinate (ArgSuc). A pre-dialysis and post-dialysis evaluation was performed in patients with chronic kidney disease by using the LC-MS/MS method.

METHODS: Mobile phase composition and column type combinations were determined in order to obtain the most ideal chromatographic separation in the shortest time for the mentioned analytes. After the chromatographic conditions were determined, the specificity, linearity, reproducibility and detection and quantification limits of the method were determined. After validation of the developed method according to CLSI documents, pre- and post-dialysis samples were collected from 38 chronic kidney failure (CKF) patients. In addition, measurements and evaluations were made in the samples taken from 34 healthy individuals.

RESULTS: When the analysis results of samples taken from patients with CKF before and after dialysis and healthy control group patients are compared, SDMA, ArgSuc, Cit, HCit values are significantly higher, while HArg values are significantly lower. ( $p<0.05$ for all). All metabolites except Arg were significantly decreased in the pre- and post-dialysis comparisons in CRF patients $(\mathrm{p}<0.05$ for all).

CONCLUSIONS: Although ADMA, SDMA, ArgSuc, Cit, HCit, HArg, ArgSuc decreased with dialysis in CKF patients, all analytes except HArg were above the levels of the healthy control group. High levels of ADMA metabolites in patients with CRF will contribute to the chronic inflammation process.

Keywords: ADMA, SDMA, Arginine, Dialysis, LC-MS/MS

\section{P-014 \\ SERUM NEUDESIN LEVELS IN PATIENTS WITH DIABETIC NEUROPATHY}

Ayfer Colak ${ }^{1}$, Anil Baysoy ${ }^{1}$, Ezgi Yildiz Yurekli², Banu Isbilen Basok 'Department of Medical Biochemistry, University of Health Sciences, Izmir Tepecik Training \& Research Hospital, Izmir, Turkey

${ }^{2}$ Department of Neurology, University of Health Sciences, Izmir Tepecik

Training \& Research Hospital, Izmir, Turkey

OBJECTIVE: Neudesin, one of the membrane-associated progesterone receptors, is a protein with neural functions that participates in energy metabolism, has a cytochrome 5-like heme/steroid-binding domain. Although the effect of this protein has been demonstrated in an experimental model of type-2 diabetes mellitus (Type-2DM), its effect in humans is unknown. Diabetic neuropathy is the most common complication of diabetes mellitus. In our study, it was aimed to evaluate the relationship of neudesin, which has been suggested to play a role in the development of metabolic and neurological disorders, and the presence of neuropathy in patients with Type-2DM.

MATERIALS-METHODS: 46 patients with diabetic neuropathy who applied to the neurology outpatient clinic and 37 control groups were included in the study. Circulating neudesin levels were measured by ELISA.

RESULTS: The mean age of the patient group was $54 \pm 7.5$ and the mean age of the control group was $35 \pm 13$. The patient group consisted of more obese people than the control group. The serum neudesin level of the patient group was $254 \pm 155 \mathrm{ng} / \mathrm{mL}$ and the serum neudesin level of the control group was $414 \pm 188 \mathrm{ng} / \mathrm{mL}$. Between the control group $(\mathrm{n}=37)$ and the patient group $(\mathrm{n}=46)$ there were significant differences in age $(\mathrm{p}<0.001)$, body mass index (BMI) $(p<0.001)$, fasting plasma glucose $(F P G)(p<0.001)$, HbA1c $(p<0.001)$, neudesin $(p<0.001)$ and urea $(p=0.005)$. With serum neudesin level in the whole study group; age $(\mathrm{p}=0.025, \mathrm{r}=-0.244), \mathrm{BMI}(\mathrm{p}=0.009, \mathrm{r}=-0.297), \mathrm{FPG}(\mathrm{p}<0.001$, $r=-415), \mathrm{HbA1c}(\mathrm{p}=0.003, \mathrm{r}=-0.351)$, and urea $(\mathrm{p}=0.049, \mathrm{r}=-0.221)$ was found to be negatively correlated. In the regression analysis, serum neudesin level $(\mathrm{OR}=0.997,95 \% \mathrm{CI}: 0.995-1.000, \mathrm{p}=0.033)$ was found to be an independent risk factor in diabetic neuropathy patients.

CONCLUSION: Considering the low serum neudesin level in the patient group and the negative correlation between serum neudesin level and FPG, BMI, serum neudesin level may be important in patients with diabetic neuropathy.

Keywords: Neudesin, Diabetes Mellitus, Neuropathy

\section{P-015 \\ EVALUATION OF THE TRIGLYCERIDE-GLUCOSE INDEX AS AN INSULIN RESISTANCE MARKER IN ADULTS WITH IMPAIRED FASTING GLUCOSE METABOLISM}

Gul Kirtil ${ }^{1}$, Medine Alpdemir ${ }^{1}$, Mehmet Fatih Alpdemir ${ }^{2}$, Mehmet Senes ${ }^{1}$ SBU Ankara Health Application and Research Center, Department of Medical Biochemistry, Ankara, Turkey

${ }^{2}$ Ankara Bilkent City Hospital, Ankara, Turkey

BACKGROUND AND AIM: The triglyceride to glucose index (TyG) have been proposed as reliable and simple alternatives for the evaluation of insulin resistance (IR). The aim of this study wav to evaluated the association between TyG and IR, with impaired fasting glucose (IFG).

METHODS: In the this study, a total of 108 adults with IFG were evaluated retrospectively, who attended the outpatient service in 2021. Clinical data were collected from medical records. Fasting glucose(FG), TG, HDL-C, and insulin concentrations was measured using Roche commercial reactive. TyG indices were calculated according to the $\operatorname{Ln}(\mathrm{glu} * \mathrm{TG}) / 2$ equation.IR was defined as a HOMA-IR.

RESULTS: In the present study, the average age was $44 \pm 12.6$ years $(71 \%$ for female, $29 \%$ for males ). The mean FG and HgA1C were $104 \pm 12,5.9 \pm 0.45$. The TyG index was $8 . .99 \pm 0.52$ and the mean HOMA-IR was $3.52 \pm 1.34$ in patients HOMA-IR had a significant positive correlation with the TyG index $(\mathrm{r}=0.292$ $\mathrm{p}=0.002)$. TyG index showed a lower ROC Area under Curve $(\mathrm{AUC}=0.698)$ than HOMA-IR index (AUC $=0.788$ ).

CONCLUSIONS: This study have shown that the TyG index may be used as a marker associated with IR in the period of IFG. However, the validity of these results should be explore with a larger population.

Keywords: HOMA-IR, Insulin resistance, TyG index, Impaired fasting glucose

\section{P-016 \\ NEUTROPHIL LYMPHOCYTE RATIO, PLATELET LYMPHOCYTE RATIO AND IMMATURE GRANULOCYTE PERCENTAGE IN PATIENTS WITH SEPSIS AND SEPTIC SHOCK}

Caner Acar $^{1}$, Serdar Kucukokudan ${ }^{2}$, S. Miray Kilincer Bozgul ${ }^{1}$,

Devrim Bozkurt ${ }^{1}$, Burcu Barutcuoglu ${ }^{3}$, Gunes $\mathrm{Ak}^{3}$

${ }^{1}$ Ege University Faculty of Medicine, Department of Internal Medicine, Izmir, Turkey

${ }^{2}$ Ege University Faculty of Medicine, Department of Medical Biochemistry, Izmir, Turkey

${ }^{3}$ Ege University Faculty of Medicine, Department of Clinical Biochemistry, Izmir, Turkey

BACKGROUND AND AIM: Sepsis is a life-threatening condition that damages the body's own tissues and organs as a result of the dysregulated host response to infections. In this study, we aimed to investigate the diagnostic and prognostic values of neutrophil lymphocyte ratio (NLR), platelet lymphocyte ratio (PLR) and immature granulocyte percentage ( $\mathrm{IG}^{\circ} \%$ ), which are among the parameters of complete blood count (CBC) in patients with sepsis and septic shock.

METHODS: This retrospective study included 164 patients $(81$ sepsis, 83 septic shock) who were hospitalized in Ege University Hospital Internal Medicine intensive care unit between September 2013 and August 2021. The inclusion criteria of the patients were hospitalization in the intensive care unit for at least three days and being older than 18 years of age. Sepsis and septic shock were classified according to sepsis-3 criteria. Demographic, clinical and laboratory data of these patients were analyzed. $\mathrm{p}<0.05$ was considered significant.

RESULTS: 28 day mortality was $25.9 \%$ and $42.2 \%$ in patients with sepsis and septic shock respectively. While there was no statistically significant difference in NLR and PLR values between the sepsis and septic shock patient groups, there was a significant difference in the IG\% and SOFA scores. (p values 0.511 , $0.559,0.004$ and $<0.001$ respectively) ROC analysis shows that the area under curve (AUC) for IG\% and SOFA score for 95\% confidence interval was 0.630 $(0.545-0.715, p=0.004)$ and $0.867(0.809-0925, p=0.000)$ respectively. Logistic regression analyzes were performed to investigate their prognostic values. While NLR, PLR and IG\% were not associated with mortality, SOFA score was associated with mortality. ( $\mathrm{p}$ values $0.216,0.901,0.352$ ve 0.002 respectively) CONCLUSIONS: Although CBC is a cheap and practical test, its diagnostic and prognostic value in sepsis and septic shock is limited. $\mathrm{IG}_{\%} \%$ can be a useful biomarker in the diagnosis of sepsis and septic shock.

Keywords: sepsis, septic shock, immature granulocyte, complete blood count 


\section{P-017 EVALUATION OF SERUM ANGIOTENSIN CONVERTING ENZYME (ACE) ACTIVITY IN PEDIATRIC PNEUMONIA PATIENTS}

Gizem Yilmaz Calik, Fatih Serin, Semih Fazli Kayahan, Kezban Cavdar Yetkin, Mehmet Senes

Department of Medical Biochemistry, Ankara Health Training and Research Center, University of Health Sciences, Ankara, Turkey

BACKGROUND AND AIM: In this study, we aimed to evaluate whether serum ACE (angiotensin converting enzyme) activity can be used in the differential diagnosis of viral and bacterial pneumonia in pediatric patients diagnosed with pneumonia.

METHODS: In the study, patient between 6 months and 13 years of age were included in the study. Pneumonia was defined according to new infiltrates seen on lung $\mathrm{x}$-ray and cough, sputum, fever, pulmonary auscultation findings consistent with pneumonia, leukocytosis or leukopenia and CRP values. Patient was defined as bacterial pneumonia $(n=21)$, viral pneumonia $(n=19)$ and healthy controls $(\mathrm{n}=46)$. Serum ACE activity was quantified using BEN Biochemical Enterprise ACE kit on Roche Cobas 6000 analyzer, CRP was performed on Roche Cobas 8000 analyzer and complete blood counts were quantified on Sysmex XN 3000 analyzer. Statistical analyzes were performed with the SPSS Ver 24 package program.

RESULTS: A significant difference was found between the patients diagnosed with pneumonia and the control group in terms of serum ACE activity $(\mathrm{p}=0.017)$, WBC count $(p=0.000)$ and neutrophil count $(p=0.003)$. While there was a significant difference in serum ACE activity between viral pneumonia and control group $(\mathrm{p}=0.016)$, no significant difference was found between bacterial pneumonia-viral pneumonia, bacterial pneumonia-control group $(\mathrm{p}>0.05)$. While leukocyte counts were significantly different between bacterial pneumonia and viral pneumonia and between bacterial pneumonia and control group $(\mathrm{p}=0.000)$, no significant difference was found between viral pneumonia and control group $(\mathrm{p}>0.05)$. The relationship between the neutrophil count and the groups was similar to the relationship between the leukocyte counts and the groups. No significant difference was found between groups and CRP. When the diagnostic value of serum ACE activity was analyzed by ROC analysis, the area under the curve was found to be 0.649 .

CONCLUSIONS: According to our findings, serum ACE activity is not an effective marker that can be used in the differential diagnosis of viral pneumonia and bacterial pneumonia. However, it can distinguish pneumonia patients from the healthy control group. We believe that the effectiveness of this marker can be better evaluated with studies to be conducted in larger patient groups.

Keywords: serum ACE activity, pneumonia, pediatrics

\section{P-018 \\ INVESTIGATION OF HEMATOLOGICAL AND INFLAMMATORY PARAMETERS IN COVID-19 INFECTION}

Yasemin Atici ${ }^{1}$, Demet Kacaroglu², Aysegul Yilmaz ${ }^{3}$, Fatih Bakir ${ }^{1}$, Bulent Ahmet Besirbellioglu ${ }^{4}$, Dogan Yucel ${ }^{1}$, Metin Yildirimkaya

${ }^{1}$ Lokman Hekim University, Faculty of Medicine, Department of Medical Biochemistry, Ankara, Turkey

${ }^{2}$ Lokman Hekim University, Faculty of Medicine, Department of Medical Biology, Ankara, Turkey

${ }^{3}$ Lokman Hekim University, Faculty of Medicine, Department of Medical

Microbiology, Ankara, Turkey

${ }^{4}$ Lokman Hekim University, Faculty of Medicine, Department of Infectious

Diseases and Clinical Microbiology, Ankara, Turkey

BACKGROUND AND AIM: In this study, we aimed to examine the changes in Neutrophil/Lymphocyte ratio (NLR), C-Reactive Protein (CRP), Ferritin, Lactate Dehydrogenase (LDH), D-Dimer and Systemic immune inflammation index (SII) parameters according to age and gender in patients with COVID-19 infection.

METHODS: A total of 322 inpatients (Female: 180, Male: 142) who applied to Lokman Hekim University Ankara Hospital between March 2019 and August 2021 and had positive PCR tests were included in the study. The patients were divided into five age groups (1st group: $1-17$ years; 2 nd group: $18-30$ years; 3 rd group: $31-45$ years; 4 th group: $46-60$ years; 5 th group: 61-92 years). Laboratory results and demographic findings of PCR-positive patients were reviewed retrospectively. WBC, NLR, CRP, Ferritin, LDH, D-Dimer, SII values of the patients included in the study were examined in the study.

RESULTS: When NLR, CRP, Ferritin, LDH, D-Dimer parameters were evaluated according to age groups, there was a significant difference $(p<0.05)$. When the first and 2nd groups were compared, there was a significant difference in the D-dimer level. When the first and 3rd groups were compared, there was a significant difference in LDH, WBC, CRP levels. When the first and 4th groups were compared, there was a significant difference in the CRP levels. When the first and 5th groups were evaluated, a significant difference was observed in the levels of Ferritin, NLR, and CRP $(\mathrm{p}<0.05)$. When the correlations of NLR, CRP, and Ferritin levels showed a moderate correlation $(\mathrm{r}=0.557, \mathrm{r}=0.408, \mathrm{r}=0.400$, respectively); No correlation was observed in NLR, D-Dimer and WBC values. When evaluated according to gender, infection-related parameters (CRP, NLR, WBC and Ferritin) were found to be higher in males $(\mathrm{p}<0.05)$. When SII values were evaluated according to age and gender, no significant difference was observed $(\mathrm{p}>0.05)$

CONCLUSIONS: Since inflammatory and prognostic markers vary in patients with COVID-19 infection, we think that it would be useful to evaluate WBC, NLR, CRP, Ferritin, LDH, D-Dimer parameters and demographic data together for the follow-up of infection.

Keywords: COVID-19, Sars-CoV-2, Ferritin, D-dimer, C-reactive protein

\section{P-019 \\ PLASMA SOLUBLE UROKINASE PLASMINOGEN ACTIVATOR RECEPTOR (SUPAR) LEVELS IN ULCERATIVE COLITIS}

Huriye Erbak Yilmaz ${ }^{1}$, Saliha Aksun², Suleyman Gunay ${ }^{3}$, Ferhan Elmali, Cem Cekic ${ }^{5}$

${ }^{1}$ Biochemistry Laboratory, Izmir Katip Celebi University Ataturk Education and Research Hospital, Izmir, Turkey; Izmir Biomedicine and Genome Center, Izmir, Turkey

${ }^{2}$ Department of Biochemistry, Izmir Katip Celebi University Ataturk Education and Research Hospital, Izmir, Turkey

${ }^{3}$ Department of Gastroenterology, Izmir Katip Celebi University Ataturk

Education and Research Hospital, Izmir, Turkey

${ }^{4}$ Department of Statistics, Izmir Katip Celebi University, Izmir, Turkey

${ }^{5}$ Department of Gastroenterology, University Of Tinaztepe, Izmir, Turkey

BACKGROUND AND AIM: Soluble urokinase plasminogen activator receptor (SuPAR), a soluble form of the urokinase-type plasminogen activator receptor, is a biomarker produced by macrophages, monocytes, neutrophils, active T cells, endothelial cells and circulating tumor cells. SuPAR is a novel biomarker showing altered inflammation in many inflammatory diseases. This study aims to investigate the SuPAR level in ulcerative colitis (UC) patients and to evaluate the SuPAR level in active and remission patients.

METHODS: Patient and healthy control SuPAR levels were analyzed by immunoassay method and SuPAR levels between UC patients and control group were compared. The difference between SuPAR levels in patients with active UC and UC in remission was analyzed. The relationship between C-reactive protein level, Total Mayo score, Mayo Endoscopic score used to predict disease activity, and amount of SuPAR were evaluated.

RESULTS: SuPAR levels were determined in the UC patient group $(2170,3 \pm 121,0$ $\mathrm{pg} / \mathrm{ml})$ and healthy controls $(2130,7 \pm 164,8 \mathrm{pg} / \mathrm{ml})(\mathrm{p}=0.805)$. Median SuPAR levels were determined in moderate UC $(2479 \mathrm{pg} / \mathrm{ml})$, mild UC $(1944 \mathrm{pg} / \mathrm{ml})$ and patients in remission $(1774 \mathrm{pg} / \mathrm{ml})(\mathrm{p}=0,207)$. There were no significant relationships between SuPAR levels and CRP levels, Total Mayo score, and disease duration in the UC group $(\mathrm{r}=0.177, \mathrm{r}=0.267$ and $\mathrm{r}=0,007$; respectively $\mathrm{p}>0.05$ ). A slightly positive correlation was found between Mayo Endoscopic Score and SuPAR level $(\mathrm{r}=0.303 ; \mathrm{p}=0.031)$

CONCLUSIONS: SuPAR is of limited value in the diagnosis of ulcerative colitis and in the assessment of disease activation.

Keywords: Biomarker, inflammatory bowel disease, mucosal inflammation, SuPAR, ulcerative colitis

\section{P-020 \\ OPTIMIZATION OF BIOACTIVE LAYER IN IMMOBILIZATION OF GLUTATHIONE REDUCTASE ENZYME}

Basak Gunasti, Abdullah Tuli

Cukurova University, Faculty of Medicine, Department of Medical Biochemistry, Adana, Turkey

BACKGROUND AND AIM: Glutathione Reductase (NADPH; GSSG oxidoreductase, E.C. 1.6.4.2) is a member of the oxidoreductase enzyme family, which converts oxidized glutathione to reduced glutathione. The Glutathione Reductase enzyme maintains the intracellular -SH/-SS- ratio by increasing the Glutathione (GSH)/Oxidized Glutathione (GSSG) ratio. In this study, Glutathione Reductase was immobilized to the bioactive layer created to design an enzymebased biosensor. It was aimed to optimize the bioactive layer, which was the basic stage in immobilization.

METHODS: BSA/Gelatin was used as the nanopolymer in the bioactive layer of the biosensor. Glutaraldehyde was used as the crosslinking agent. Triple electrode system was used in potentiometric measurements. Biosensor responses were evaluated at $\mathrm{pH} 7.8$, a concentration of $100 \mathrm{mM}$ phosphate buffer, and a temperature of $35^{\circ} \mathrm{C}$. Increasing volume $(5,6,7,8,9,10$ microliters) of BSA Gelatin polymer was prepared. In this study, the effects of different percentages of glutaraldehyde, which was used as a cross-linking agent, on the biosensor response were investigated.

RESULTS: It was determined that the optimum sensor response of the Glutathione Reductase enzyme was obtained in $5 \mu \mathrm{L}$ BSA/Gelatin. The highest sensor response of the Glutathione Reductase enzyme was observed at $2 \%$ glutaraldehyde concentration. The amount of Glutathione Reductase enzyme was constant at $5 \mu \mathrm{L}$.

CONCLUSIONS: In enzyme-based biosensor studies, immobilization parameters are the basis of the sensor system. It was concluded that determining the optimum amount of each immobilization measurement conditions gave the most accurate 
and fast response in the biosensor. In the next step, interference studies will be carried out.

Keywords: Biosensor, Glutathione Reductase, Optimization

\section{P-021 \\ IN VITRO AND IN SILICO EVALUATION OF THE INHIBITORY EFFECTS OF AUXINS ON HUMAN PLACENTAL GLUTATHIONE S-TRANSFERASE P1-1}

Pavel Husamadin ${ }^{1}$, Ozlem Dalmizrak ${ }^{1}$, Kerem Terali $^{2}$, Nazmi Ozer ${ }^{3}$ ${ }^{1}$ Department of Medical Biochemistry, Faculty of Medicine, Near East University, Nicosia, TRNC

${ }^{2}$ Department of Medical Biochemistry, Faculty of Medicine, Girne American University, Kyrenia, TRNC

${ }^{3}$ Department of Biochemistry, Faculty of Pharmacy, Girne American University, Kyrenia, TRNC

BACKGROUND AND AIM: Glutathione S-transferases (GSTs) is a family of phase II enzymes which detoxify xenobiotics in the body through catalyzing their conjugation to glutathione. Implication of GSTs in detoxification process can result in a multifactorial phenomenon termed as multidrug resistance (MDR) in cancer patients. Therefore, GST superfamily is now extensively targeted in the attempt to develop more competent chemotherapeutic agents for treating cancer. Auxins which are a class of plant hormones that play crucial role in plant growth and development. Particularly, indoleacetic acid is known to bind GST and regulate its function in plants. In this study three classes of auxins, indoleacetic acid (IAA), indolepropionic acid (IPA) and indolebutyric acid (IBA) were examined for their inhibitory effect on hpGSTP1-1 as a mean to reduce its activity and combat MDR in patients undergoing chemotherapy.

METHODS: Different auxin concentrations $(0.3125-10 \mathrm{mM})$ were tested for the estimation of IC50 values. Then inhibitory kinetic experiments were carried out at four chosen inhibitor concentrations $(0.25,0.5,1$ and $2 \mathrm{mM})$. The inhibition types and kinetic parameters were determined from graphs and SPSS version 20 . The structural basis for the interaction between hpGSTP1-1 and auxins were predicted using molecular docking.

RESULTS: All three classes of auxins inhibit the activity of hpGSTP1-1 in a competitive manner in respect to both substrates. Their IC50 values were calculated as 9.7, 7.2 and 7.0 mM for IAA, IPA and IBA, respectively. These inhibitory auxins were predicted to be stabilized mainly by the hydrophilic amino acid residues that are located at the glutathione-binding site (G-site) of the enzyme.

CONCLUSIONS: Our integrated in vitro and in silico study reveals the ability of auxins to inhibit hpGSTP1-1, so that they could be considered in the development of novel drugs which are less cytotoxic and effective at very low concentrations. Keywords: Human placental glutathione S-transferases, indoleacetic acid, indolepropionic acid, indolebutyric acid, inhibition kinetics, molecular docking

\section{P-022 \\ COMPARISON OF THE EFFECTS OF MISTLETOE EXTRACT AND N-ACETYL CYSTEINE ON VITAMIN D LEVELS IN IONIZED RADIATION EXPOSURE}

$\underline{\text { Hakan Vatansev }}^{1}$, Fatma Sengul ${ }^{2}$, Fadime Ovali $^{3}$, Bahadir Ozturk ${ }^{3}$,

Fikret Akyurek $^{3}$, Husamettin Vatansev ${ }^{3}$

${ }^{1}$ Necmettin Erbakan University, Meram Vocational High School, Department of Food Processing, Konya, Turkey

${ }^{2}$ Adiyaman University, Faculty of Pharmacy, Department of Basic

Pharmaceutical Sciences, Adiyaman, Turkey

${ }^{3}$ Selcuk University, Faculty of Medicine, Department of Clinical Biochemistry, Konya, Turkey

BACKGROUND AND AIM: It is observed that vitamin D levels and many related biological functions are negatively affected in patients after chemotherapy and radiotherapy. Many studies have shown that different mistletoe extracts have a strong cytotoxic effect on cancer cells, contribute to reducing the side effects of chemotherapy and radiotherapy, and have a regulatory role on the immune system. In our study, we aimed to compare serum vitamin D levels in irradiated experimental animals by combining ethanol extract obtained from mistletoe collected from almond trees, whose radioprotective effects we investigated, alone or in combination with n-acetyl cysteine (NAC).

METHODS: Mistletoe extract was obtained by the soxhlet extraction method. In the 14-day experimental study, 38 Wistar albino male rats, 6-10 weeks old, were used. Working groups; control( $\mathrm{n}=6)$,radiotherapy $(\mathrm{RT})(\mathrm{n}=8), \mathrm{RT}+$ Mistletoe(VA) $(\mathrm{n}=8), \mathrm{RT}+\mathrm{NAC}(\mathrm{n}=8), \mathrm{RT}+\mathrm{VA}+\mathrm{NAC}(\mathrm{n}=8)$ Edited. On the first day of the study, a single dose of 12 GyRT was applied to the groups to be treated with RT. During the experiment, $500 \mathrm{mg} / \mathrm{kg}$ of mistletoe extract was administered by gavage and $275 \mathrm{mg} / \mathrm{kg} / 48$ hours of NAC was administered intraperitoneally to the relevant groups every day. At the end of the 14th day, samples were collected by blood collection from the heart under anesthesia. At the end of the study, 2 animals from each group died. The blood samples were centrifuged at $3500 \mathrm{rpm}$ for 10 minutes and the serum part was separated. Vitamin D levels in serum samples were analyzed by LC-MS/MS device. Statistical analysis IBM SPSS 20.0. non- parametric tests with the program; It was performed using Kruskal-Wallis rank one-way analysis of variance and Mann-Whitney-U tests.

RESULTS: Compared to the control group; Vitamin D levels decreased in the RT andRT+VA groups, respectively $(\mathrm{p}=0.016, \mathrm{p}=0.010)$, while there was no significant difference in theRT+NAC, RT+VA+NAC groups $(\mathrm{p}=0.273, \mathrm{p}=0.144)$. compared to the RT group; There was no significant difference in the RT+VA, RT+NAC, RT+VA+NAC groups $(\mathrm{p}=0.749, \mathrm{p}=0.068, \mathrm{p}=0.584)$..

CONCLUSIONS: When our results are examined,it is seen that ethanolic almond mistletoe extract cannot prevent the regression of vitamin D levels when used alone. Although there is no significant difference, studies with longer experimental times will reveal the effect of almond mistletoe extract and NAC combination more clearly that the combination of almond mistletoe extract may be more effective

Keywords: Radiation, mistletoe extract, N-Acetyl Cysteine, vitamin D.

\section{P-023 \\ THE RELATIONSHIP OF NEUTROPHIL AND LYMPHOCYTE VOLUME PARAMETERS WITH GESTATIONAL DIABETES}

Muammer Ozdemir, Menekse Kuzu, Duygu Eryavuz Onmaz, Sedat Abusoglu Selcuk Univercity Medical Faculty Department of Medical Biochemistry, Konya, Turkey

BACKGROUND AND AIM: Pregnancy is a condition characterized by many physiological hematological changes which could be considered pathological in the usual condition. When leukocytosis caused by the physiological stress caused by pregnancy is examined, it is seen that the most increased type of leukocyte is neutrophils. Mean Neutrophil Volume (MNV) and Mean Lymphocyte Volume; (MLV) come out as new markers of activated neutrophils and lymphocytes. Gestational Diabetes Mellitus (GDM) also goes with an inflammatory response that creates insulin resistance. In this study, we investigated the Mean Neutrophil and Mean Lymphocyte Volumes; comparing with Gestational Diabetes Mellitus patients and control group and; analyzed the change of Neutrophil and Lymphocyte Volumes in GDM.

METHODS: 50 pregnant woman who has gestationel diabetes mellitus and applied to the Medical Biochemistry Laboratory of Selcuk University Medical Faculty Hospital in the last year and complete blood count was studied were included in the study. As the control group, 50 pregnant women without any chronic disease were selected. Neutrophil and lymphocyte volumes were studied retrospectively.

RESULTS: All of the patients were pregnant, mean age was 31.6 for the patien group and 31.3 for the control group. There was no statistically significant difference between the patient and control groups in terms of mean age. Neutrophil volume was found to be $146 \mathrm{fL}(133-1519)$ and $144 \mathrm{fL}(132-1475)$ in the patient and control groups, respectively, $p=0.137$, and there was no significan relationship between them. Lymphocyte volume was found to be $87 \mathrm{fL}$ (81-854) in the patient group and $84 \mathrm{fL}(78-882)$ in the control group and the $\mathrm{p}=0.005$, and there is a significant relationship between them.

CONCLUSIONS: With further studies in this field, Neutrophil and Lymphocyte Volume parameters can be used as a risk marker for GDM by using it with some other risk factors.

Keywords: Pregnancy, Gestational Diabetes, Complete blood count, Neutrophil, Lymphocyte

\section{P-024 \\ EVALUATION OF METABOLITE PROFILES OF FORMALIN-FIXED AND PARAFFIN-EMBEDDED TISSUES BY MALDI-IMAGING MASS SPECTROMETRY}

Busra Ergun $^{1}$, Emel Akgun ${ }^{1}$, Fatma Tokat ${ }^{2}$, Umit Ince ${ }^{2}$, Aysel Ozpinar ${ }^{3}$, Yasemin $\mathrm{Ucal}^{3}$

${ }^{1}$ Acibadem Mehmet Ali Aydinlar University, Institute of Health Sciences, Department of Biochemistry and Molecular Biology, Istanbul, Turkey ${ }^{2}$ Acibadem Mehmet Ali Aydinlar University, Faculty of Medicine, Department of Medical Pathology, Istanbul, Turkey

${ }^{3}$ Acibadem Mehmet Ali Aydinlar University, Faculty of Medicine, Department of Medical Biochemistry, Istanbul, Turkey

BACKGROUND AND AIM: Metabolites are compounds less than approximately $1,500 \mathrm{Da}$ that reflect the starting molecules, products, and intermediates of metabolic pathways. The number of studies on the metabolite profiles of formalin-fixed and paraffin-embedded (FFPE) tissues is limited, since fixation with formalin may alter the metabolite content of the tissue and potentially cause metabolite loss due to potential changes. However, chemical and spatial preservation of metabolites has been demonstrated by histology-based matrix-assisted laser desorption/ionization (MALDI) imaging mass spectrometry studies. This study aimed to evaluate the effect of different MALDI matrix application parameters of metabolite profiles in FFPE thyroid tissue.

METHODS: The thyroid tissue sample were sectioned with a microtome at 3 um onto conductive indium tin oxide (ITO) coated slide. After the tissue was heat treated, it was washed with xylene. Two different 9-Aminoacridine (9-AA) matrix concentrations $(10 \mathrm{mg} / \mathrm{ml}$ and $2 \mathrm{mg} / \mathrm{ml})$ prepared in $70 \%(\mathrm{v} / \mathrm{v})$ methanol 
were used to coat the tissues with matrix. The slides were coated with 9-AA matrix by adjusting different nozzle positions $(Z=25 \mathrm{~mm}, Z=15 \mathrm{~mm})$ using the Sun Collect (Sun Chrome GmbH) device. Analyzes on RapifleX MALDI Tissue Typer (Bruker Daltonics) mass spectrometer in negative-ion reflectron mode over the $\mathrm{m} / \mathrm{z}$ range of 50 to 1000 .

RESULTS: When the matrix density was increased in FFPE thyroid tissue, more metabolite peaks were detected. While the tissues were coated with $10 \mathrm{mg} /$ $\mathrm{ml}$ 9-AA matrix, the metabolite peak number was higher at $Z=25 \mathrm{~mm}$ nozzle position, but the metabolite peak with the highest signal intensity $(\mathrm{m} / \mathrm{z} 193.3)$ was selected for both nozzle positions and as a result of 3 replications analysis. There was no significant difference in the signal intensities at two different nozzle positions $(\mathrm{p}>0.05)$.

CONCLUSIONS: In the investigation of metabolites by MALDI-Imaging mass spectrometry, it is important to analyze the matrix application parameters along with the comparison of different matrix concentrations. Of the different parameters applied in this study, the application of $10 \mathrm{mg} / \mathrm{ml} \mathrm{9-AA}$ matrix concentration with a $25 \mathrm{~mm}$ nozzle position resulted in more metabolite peaks. Acknowledgments: This work was supported by TUBITAK 1002 grant (219S169).

Keywords: MALDI-Imaging Mass Spectrometry, Metabolite Profiling, Matrix Optimization, FFPE

\section{P-025 \\ DEVELOPING ALGORITHMS TO PREVENT FALSE HBA1C RESULTS IN INDIVIDUALS WITH HEMOGLOBIN VARIANT AND HIGH HEMOGLOBIN F LEVELS}

\section{Esra Yildirim Demircin ${ }^{1}$, Gamze Gok ${ }^{1}$, Funda Eren ${ }^{1}$, Turan Turhan ${ }^{1}$, Gulsen Yilmaz ${ }^{2}$}

${ }^{1}$ TC Ministry of Health Ankara City Hospital Medical Biochemistry Clinic, Ankara, Turkey

${ }^{2}$ TC Ministry of Health Ankara City Hospital Medical Biochemistry Clinic, Ankara Yildirim Beyazit University Faculty of Medicine, Department of Medical Biochemistry, Ankara, Turkey

BACKGROUND AND AIM: HbA1c measurements which is commonly used in diabetes patients' most common interferences are due to $\mathrm{Hb}$ variants and high $\mathrm{HbF}$ levels. Our aim in this study is to develop an in-laboratory algorithm that prevents erroneous HbA1c results by evaluating HbA1c results retrospectively. METHODS: The results of individuals who simultaneously had HbAlc measurement and Hemoglobin Variant analysis by capillary electrophoresis method between February and August 2021 were obtained from the Laboratory Information System (LIS). $\mathrm{HbF}$ levels and presence of $\mathrm{Hb}$ variant, which are the sources of interference that may affect $\mathrm{HbAlc}$ test results, were evaluated.

RESULTS: In our study, 59,624 $\mathrm{HbAlc}$ results and 1026 simultaneous $\mathrm{Hb}$ electrophoresis analyzes were evaluated. In patients with $\mathrm{Hb}$ variant, $\mathrm{HbAD}$ $35.9 \%(\mathrm{n}=14)$, HbSS $28.20 \%(\mathrm{n}=11)$; HbAS $28.20 \%(\mathrm{n}=11)$; HbAC $2.56 \%(\mathrm{n}=1)$, $\mathrm{HbDD} 2.56 \%(\mathrm{n}=1)$ and $\mathrm{HbXX} 2.56 \%(\mathrm{n}=1)$ was determined respectively. $\mathrm{Hb} \mathrm{F}$ values of 24 patients $(2.3 \%)$ were higher than $23 \%$. HbSS was present in $20.8 \%$ $(n=5)$ of the patients with this $\mathrm{Hb} F$ elevation. In total, 24 patients with elevated $\mathrm{HbF}$, and additionally 13 patients with Homozygous $\mathrm{Hb}$ variants, were likely to have a false $\mathrm{HbA} 1 \mathrm{c}$ result.

CONCLUSIONS: An in-laboratory algorithm was developed to prevent misleading $\mathrm{HbA} 1 \mathrm{c}$ measurement in individuals with a hemoglobin variant and high hemoglobin $\mathrm{F}$ levels. According to this algorithm, the results of individuals with Homozygous and Compound Heterozygous $\mathrm{Hb}$ variants were considered as invalid and individulas are recommended to use fructosamine and glycealbumin measurements as the alternative tests for glycemic control.In the presence of heterozygous $\mathrm{Hb}$ variant, adding the detected variant to the LIS and validating the results was included in the algorithm. Thus, an in-laboratory algorithm was developed to prevent misleading HbA1c results in individuals with a hemoglobin variant and high hemoglobin $\mathrm{F}$ levels.

Keywords: HbA1c, Rational laboratory use, capillary electrophoresis, sources of interference, $\mathrm{Hb}$ variant analysis

\section{P-026 \\ DIFFERENTIAL DIAGNOSIS OF PSEUDOHYPERPHOSPHATEMIA IN A CASE WITH PARAPROTEINEMIA}

Lacin Celik, M. Andac Temel, Cetin Uzun, Burcu Barutcuoglu Ege University Faculty of Medicine, Department of Medical Biochemistry, Izmir, Turkey

BACKGROUND AND AIM: In Multiple Myeloma (MM), cancer of plasma cells, test interferences due to increased paraprotein can be seen. In this case report, preanalytical preparation to determine whether the cause of hyperphosphatemia in a patient with MM with clinically inconsistent hyperphosphatemia is paraproteinrelated interference is discussed.

METHODS: The serum phosphate level of a 66-year-old female patient diagnosed with MM 5 years ago was measured high $(17 \mathrm{mg} / \mathrm{dL})$ inconsistently with the clinic. The patient's total protein level is $112.3 \mathrm{~g} / \mathrm{L}$, albumin is 32.8 $\mathrm{g} / \mathrm{L}$ and globulin is $79.5 \mathrm{~g} / \mathrm{L}$. Phosphate levels were measured with the photometric ammonium molybdate method in the Roche Cobas 702 device by applying 4 different preanalytical procedures for the differential diagnosis of the case, which was thought to be a spurious hyperphosphatemia as a result of paraprotein interference. In the 1 st procedure, the serum was diluted only $1: 1$. In the 2nd procedure, $500 \mu \mathrm{L}$ of the sample was diluted $1: 1$, then $100 \mu \mathrm{L}$ of $20 \%$ trichloroacetic acid (TCA) to precipitate paraproteins and $60 \mu \mathrm{L}$ of $1.5 \mathrm{~N}$ sodium hydroxide $(\mathrm{NaOH})$ as a buffer were added. In the 3 rd procedure, the same amount of TCA and $\mathrm{NaOH}$ was added to $500 \mu \mathrm{L}$ of serum. In the 4 th procedure, after 1:1 dilution, $100 \mu \mathrm{L}$ of $20 \%$ TCA was added to $500 \mu \mathrm{L}$ of the sample.

RESULTS: The total protein $(\mathrm{g} / \mathrm{L})$ and phosphate $(\mathrm{mg} / \mathrm{L})$ levels obtained after the procedures are as follows: 1st procedure 109/16.2; 2nd procedure 18/2.02; 3 rd procedure $1 / 0.43$; 4 th procedure $19 / 4.62$. Although no significant change was observed with only dilution, phosphate levels were found too low to be clinically compatible in diluted and undiluted samples with precipitation and buffering. It was thought that the high $\mathrm{pH}$ created by $\mathrm{NaOH}$ caused the spontaneous reduction of molybdate. Phosphate value obtained in the 4th process with dilution and TCA precipitation was measured at the most compatible level with clinic.

CONCLUSIONS: Since hyperphosphatemia is a serious electrolyte problem that usually progresses asymptomatically, clinical and laboratory cooperation and exclusion of paraprotein interference in phosphate measurements are important for patient health. In this case, with predicted pseudo-hyperphosphatemia, the differential diagnosis was confirmed by preanalytical procedures, and unnecessary/incorrect treatment was prevented.

Keywords: pseudohyperphosphatemia, paraproteinemia, Multiple myeloma

\section{P-027 \\ AN ANALYTICAL INTERFERENCE FACED DURING A STUDY ON A COMMERCIAL SPECIES-SPECIFIC ELISA KIT}

Gulinnaz Ercan ${ }^{1}, \underline{\text { Cetin Uzun }}^{1}$, Burcu Denizlioglu ${ }^{1}$, Hilal Kabadayi ${ }^{2}$,

H. Seda Vatansever ${ }^{2}$

${ }^{1}$ Ege University Faculty of Medicine, Department of Medical Biochemistry, Izmir, Turkey

${ }^{2}$ Celal Bayar University Faculty of Medicine, Department of Histology and Embryology, Manisa, Turkey

BACKGROUND AND AIM: The phenomenon that occurs when an antibody specifically targeted to one antigen is successful in binding to another antigen is called cross-reactivity. In this study, it is aimed to indirectly show that crossreactivity occurs in the analysis made in a commercial ELISA kit and to report the experience gained.

METHODS: In our study, two groups were formed using athymic CD1 nude mice to create a heterotopic tumor model with the PANC1 cell line. Natura killer cells (NKcs) derived from human umbilical cord mesenchymal stem cells (h-UKMSCs) administered intravenously, ELISA kits measuring human plasma granzyme B, perforin and interferon- $\gamma(\mathrm{INF}-\gamma)$ levels to determine the cytotoxic activity of NKc (Sunred Biological Technology Ltd, Shanghai, China). Since the NKc of the mouse will be stimulated with the interleukins (IL-2, IL-15) applied to the mouse in the NKc treatment, the human kit was preferred to avoid crossreactivity.

RESULTS: In the cytokine-treated untreated tumor group (control), granzyme B: $163.1-207.7 \mathrm{ng} / \mathrm{L},(179.5 \pm 15.5 \mathrm{ng} / \mathrm{L})$; perforin: $90.1-198.7 \mathrm{ng} / \mathrm{L},(133.2 \pm 40.1$ $\mathrm{ng} / \mathrm{L}) ; \mathrm{INF}-\gamma: 8.8-23.4 \mathrm{ng} / \mathrm{L},(17.2 \pm 5.4 \mathrm{ng} / \mathrm{L})$ were found on the other hand In the group of tumors originating from h-UKMSC treated with $\mathrm{NKc}$ (treatment) granzim B: $162.2-201.3 \mathrm{ng} / \mathrm{L},(178.4 \pm 12.4 \mathrm{ng} / \mathrm{L})$; perforin: $138-156.6 \mathrm{ng} / \mathrm{L}$ $(147.1 \pm 7.7 \mathrm{ng} / \mathrm{L})$; INF- $\gamma$ : 12.2-25 ng/L, $(18.6 \pm 4.2 \mathrm{ng} / \mathrm{L})$ were measured. Groups were determined within the reference range provided by the kit.

CONCLUSIONS: While the control group carried only mouse NKc; the treatment group also had human NKc. Our aim was to measure human NKc secretions. However, the human ELISA kits used in the study also measured in the reference range in the control group measurements where only mouse $\mathrm{NKc}$ was present. This suggested that the ELISA kit had low specificity or was susceptible to cross reactivity. Due to these results, which will cast doubt on the reliability of the data obtained from the use of commercial ELISA kits in experimental models, it is important to make more stringent controls in kit production and to share such problems with the scientific community.

Keywords: Natural Killer Cell, ELISA, Granzyme B, Perforin, Interference, Cross Reactivity

\section{P-028 \\ COMPARISON OF NA, K AND CL VALUES MEASURED BY BLOOD GAS ANALYZER AND LABORATORY AUTOANALYZER}

Neslihan Sungur, Ayse Ulusoy, Hatice Saracoglu, Didem Barlak Keti, Sabahattin Muhtaroglu

Erciyes University, Department of Research Biochemistry, Kayseri, Turkey

BACKGROUND AND AIM: Electrolytes are one of the most frequently measured analytes with physiological significance for many body functions. The concentration of plasma electrolytes is routinely assessed with a blood gas device (direct IFSE) or laboratory autoanalyzer (indirect IFSE). The results of electrolyte values in biochemistry laboratories 
take much longer than blood gas devices. In addition, factors such as serum protein and lipid disorders also affect the results. The ideal anticoagulant for blood gas measurement is lithium heparin. However, $\mathrm{Na}$-heparin is routinely used as an anticoagulant due to its cost and easy availability. This application causes sodium contamination and causes a false high value. In our aim; to determine the difference in sodium level of Na-heparin use and to investigate the usability of $\mathrm{Na}, \mathrm{K}$ and $\mathrm{Cl}$ values from blood gas electrolytes instead of autoanalyzer electrolyte values.

METHODS: Venous blood samples were collected from 10 healthy volunteers into gel biochemistry tube, tube with Li-heparin, insulin syringes washed with Li-heparin and Na-heparin. The $\mathrm{Na}, \mathrm{K}$ and $\mathrm{Cl}$ levels of Li- and Na-heparinized whole blood samples were studied in the existing blood gas device (siemens RAPIDLAB 1200), and serum samples in the existing autoanalyzer (Cobas e801). RESULTS: When serum indirect ISE and direct ISE with Li-heparin and direct ISE with Li-heparin were compared with Na-heparin direct ISE, $\mathrm{Na}$ and $\mathrm{K}$ were both statistically and clinically significant $(<0.001)$. When serum indirect ISE and $\mathrm{Na}$-heparin direct ISE were compared, $\mathrm{Na}$ and $\mathrm{K}$ were found to be statistically significant $(<0.05,<0.001)$

CONCLUSIONS: It is not appropriate to use $\mathrm{K}$ and Na measurement results with blood gas analysis instead of measurement results with autoanalyzer. Factors such as the different types of samples used during the two analyzes, sodium contamination, and holding the samples may play a role in the inconsistency between the autoanalyzer and blood gas results.

Keywords: Blood gas, Electrolytes, Anticoagulant

\section{P-029 \\ INVESTIGATION OF THE DNA POLYMERASE INHIBITOR PNR7-02 EFFECT ON CISPLATIN TREATED MCF-7 BREAST CANCER CELLS}

Onur Aktan, Gulnihal Kulaksiz Erkmen

Department of Medical Biochemistry, Hacettepe University Faculty of Medicine, Ankara, Turkey

BACKGROUND AND AIM: Breast cancer is the most common cancer type among women. The most important limiting factor in the cancer drug treatment is the drug resistance development. Cisplatin is a platinum group drug frequently used in many types of cancer including breast cancer. It achieves its effects by causing damage to DNA and killing cancer cells. DNA damage tolerance mechanisms may reduce these effects, and may lead to cisplatin resistance development. The most important enzyme in damage tolerance is DNA polymerase eta(Poleta), and its inhibition in HAP1 and over cancer cells could increase cisplatin efficacy. The aim of this study is to investigate how PNR-7-02, a Poleta inhibitor affects cell viability in cisplatin-treated/untreated MCF-7 breast cancer cells.

METHODS: MCF-7 cell lines grown in DMEM containing 10\%FBS, 100ug/ $\mathrm{ml}$ penicillin- streptomycin in an incubator containing $5 \% \mathrm{CO} 2$, seeded at 6000cells/well in a 96-well plate and kept for 24 hours. Cisplatin and/or PNR7-02 administered for 24-48 hours at different doses, and cell viability measured by MTT method, Combination indexes(CI) calculated by CompuSyn software. RESULTS: Cisplatin and PNR-7-02 decreased cell viability when administered alone. The IC50 values after 24 and 48 hours of drug administration were $21.46 \pm 1.10 \mu \mathrm{M}$ and $13.15 \pm 1.03 \mu \mathrm{M}$ for cisplatin, $18,17 \pm 1,09 \mu \mathrm{M}$ and $12,83 \pm 1,07 \mu \mathrm{M}$ for PNR-7-02, respectively. Our data shows that the administration of PNR-7-02 together with cisplatin increases the effectiveness of cisplatin at low concentrations.

CONCLUSIONS: PNR-7-02/cisplatin administration alone has cytotoxic effects on MCF-7 cells. According to CI values, PNR7-02 and cisplatin were mostly synergistic at low concentrations. This study was supported by Hacettepe University Scientific Research Projects_Coordination_Unit, project numbere $\bar{d}$ TYL-2020-18767.

Keywords: Breast cancer, Cisplatin, DNA polymerase eta, DNA damage tolerance, PNR-7-02

\section{P-030 \\ GANODERMA APPLANATUM MODULATION OF NF-KB INHBITION VIA COLONY FORMATION}

Sureyya Erturk ${ }^{1}$, Sinan Aktas $^{2}$, Serdar Karakurt ${ }^{1}$

${ }^{1}$ Department of Biochemistry, Selcuk University, Konya, Turkey

${ }^{2}$ Department of Biology, Selcuk University, Konya, Turkey

BACKGROUND AND AIM: Inflammatory bowel diseases are known to cause colon cancer. In cancers caused by inflammatory bowel diseases, suppression of the tumor occurs by NF-kB inhibition. NF-kB causes an increase in reactive oxygen species in the cell. Ganoderma applanatum is a fungus with important biological properties. It was aimed to investigate the effects of Ganoderma applanatum fungus on NF- $\mathrm{KB}$ gene and protein expression in colon cancer cells DLD-1 and HT-29 cells.

METHODS: The cytotoxicity studies of Ganoderma applanatum extracts in colon cancer cells and colon healthy epithelial cells were determined fluorometrically using the Alamar blue method. Colon cancer cells were treated with the extracts at the IC50 value calculated with the aid of the sigmoidal graph. Molecular analyzes were performed by qRT-PCR methods.
RESULTS: The IC50 value of Ganoderma applanatum methanol extract in DLD1 and HT-29 cells, which are colon cancer cells, was $20.79 \mu \mathrm{g} / \mathrm{mL}$ and $140 \mu \mathrm{g} / \mathrm{mL}$, respectively, while it was $189 \mu \mathrm{g} / \mathrm{mL}$ in healthy colon epithelial cells CCD-18Co found. It was determined that there was a $90 \%$ inhibition in DLD1 cells. It was determined that there was a 3 -fold decrease in NF-kB gene expression in DLD-1 and 3.5 -fold decrease in HT-29 cell.

CONCLUSIONS: When the findings were evaluated, it was determined that there was a decrease in NF-kB gene and protein expression in cells treated with Ganoderma applanatum. In this context, it has been observed that there is a decrease in the colony formation potential with migration and invasion associated with the NF-kB signaling pathway

Keywords: Colon Cancer, Colony Formation, \{Ganoderma applanatum\}, Inflamation, $\mathrm{NF}-\kappa \mathrm{B}$

\section{P-031 \\ KAEMPFEROL MODULATES PROSTATE CANCER ASSOCIATED PATHWAYS}

Halime Seyma Akalin, Hatice Gul Batur, Serdar Karakurt Department of Biochemistry, Selcuk University, Konya, Turkey

BACKGROUND AND AIM: The high prevalence of prostate cancer and the lack of expected results in treatments provide opportunities for new searches. Herbal agents such as flavonoids, with their biosafety, make them a very interesting agent for the treatment of prostate cancer. One of the flavonoids frequently used in cancer treatment is kaempferol. Kaempferol has been found to inhibit the viability of cancer cells. However, it has not been clarified by which cellular pathways it leads to cell death. The study aims to explain the effect of kaempferol on WNT/ $\beta$-catenin and MAPK pathways at the molecular level.

METHODS: For this purpose, the cytotoxic effect of kaempferol on prostate cancer cell PC-3 and healthy prostate epithelial cell PNT1A was found using Alamar Blue reagent. In addition, the changes in the expression of Kras, APC, and MLH-1 genes in the pathways encountered in prostate cancer were found by the qRT-PCR method.

RESULTS: The cytotoxic effect of kaempferol was found to be $16.9 \mu \mathrm{M}$ in PC-3 cells and $206.4 \mu \mathrm{M}$ in PNT1A cells. As a result of gene expression studies, it was determined that kaempferol decreased the expression of the Kras gene by 5.87 fold. It increased APC gene expression 3.15-fold and MLH-1 gene expression 4.36-fold.

CONCLUSIONS: As a result, kaempferol was able to differentiate between cancer cells and healthy cells. It has led to the death of cells by modulating many pathways in cancer formation. All these results show that kaempferol may be an interesting treatment method in the treatment of prostate cancer.

Keywords: Cytotoxicity, Kaempferol, Prostate Cancer, Signaling Pathways

\section{P-032 \\ MOLECULAR MECHANISM OF CYTOTOXIC EFFECT OF VIBURNUM OPULUS FRUIT EXTRACT ON HUMAN COLORECTAL CARCINOMA}

$\underline{\text { Serdar Karakurt }}^{1}$, Gulsum Tekin Abusoglu ${ }^{1}$, Zekiye Ceren Arituluk ${ }^{2}$

${ }^{1}$ Selcuk University, Faculty of Science, Department of Biochemistry, Konya, Turkey

${ }^{2}$ Hacettepe University, Faculty of Pharmacy, Department of Pharmaceutical Botany, Ankara, Turkey

BACKGROUND AND AIM: Viburnum opulus L is a traditional medicinal plan belonging to Adoxaceae family. The fruits have been used as folk medicine for kidney stones, duodenal ulcers, tension, cold, and cough in some countries. In this study, we aimed to determine the cytotoxic effect of methanol extract of V. opulus fruits (EVO) on human colorectal carcinoma (hCRC) cell lines including DLD-1, HT-29, SW-620, and Caco-2 and clarify the molecular mechanism of this cytotoxicity by investigating protein and mRNA expressions of colorectal cancer key genes; APC, MLH1, TP53, SMAD4, KRAS, and BRAF1 in these cell lines. METHODS: Fresh fruits of V. opulus were crushed and extracted with methanol. The filtered extract concentrated to dryness and lyophilized. Cell viability was determined using Alamar Blue method. Gene and protein expressions were determined by qRT-PCR and western blot analyses, respectively. RESULTS: EVO was found cytotoxic against the proliferation of hCRC cells. The IC50 value of EVO on DLD-1 cells was calculated as $254.3 \mu \mathrm{g} / \mathrm{mL}$. In additon, it was found that EVO treatment was significantly decreased $(21 \% ; \mathrm{P}=0.014)$ the BRAF1 protein expression as well as mRNA level.

CONCLUSIONS: In this study, we have clarified the molecular mechanism of the cytotoxic effects of the fruit extract of V. opulus against hCRC. EVO could inhibit tumor growth via TGF- $\beta$, MAPK, wnt, and PI3K-Akt signaling pathways and might be a promising therapeutic agent against hCRC. This study was supported by TUBITAK (Project no: 217Z279)

Keywords: Cell Signaling, Colorectal carcinoma, Gene Expresion, Protein Expression, Viburnum opulus 


\section{P-033 \\ INVESTIGATION OF CYTOTOXIC AND APOPTOTIC EFFECTS OF GANODERMA APPLANATUM EXTRACT IN HUMAN COLON CANCER CELL}

Kemal Bas ${ }^{1}$, Sureyya Erturk ${ }^{2}$, Sinan Aktas $^{3}$, Serdar Karakurt ${ }^{2}$

${ }^{1}$ Department of Biochemistry, Faculty of Science, Selcuk University, Konya, Turkey; Department of Emergency Aid and Disaster Management, Beysehir Ali Akkanat School of Applied Sciences, Selcuk University, Konya, Turkey

${ }^{2}$ Department of Biochemistry, Faculty of Science, Selcuk University, Konya, Turkey

${ }^{3}$ Deparment of Biology, Faculty of Science,Selcuk University, Konya, Turkey

BACKGROUND AND AIM: This study aims to examine the effects of Ganoderma applanatum methanol extract (GAME), which is in the group of medicinal mushrooms, on the proliferation of human colorectal carcinoma (hCRC) at the molecular level.

METHODS: After GAME extraction by the maceration method, hCRC cells, DLD-1, HT-29 cells, and healthy colon epithelial cells, CCD18-Co were treated with various concentrations of GAME ranging from 0 to $250 \mu \mathrm{g} / \mathrm{mL}$ and incubated at $37^{\circ} \mathrm{C}$ for 48 hours. The mechanism of cell death was determined using flow cytometry with Annexin V-APC and 7-AAD dyes.

RESULTS: The IC50 values of DLD-1, HT-29, and CCD18-Co cells were found to be $20.79 \mu \mathrm{g} / \mathrm{mL}, 140 \mu \mathrm{g} / \mathrm{mL}$, and $189 \mu \mathrm{g} / \mathrm{mL}$, respectively. In the apoptosis analysis, early apoptosis increased by $2 \%$ and late apoptosis by $4.6 \%$ in cells treated with GAME compared to the control group for DLD-1 cells. For HT29 , early apoptosis was increased by $59.1 \%$ and late apoptosis by $3.5 \%$ in cells treated with GAME compared to the control group.

CONCLUSIONS: It was determined that GAME possesses selective and dosedependent cytotoxicity against hCRC cells. In this context, the proliferation of hCRC cells was inhibited with a concentration below the cytotoxic value required for healthy colon epithelial cells. Furthermore, it has been found that GAME causes cells to die in a controlled manner, especially by promoting early apoptosis. The mechanism of apoptosis will be elucidated by gene and protein expression studies.

Keywords: Apoptosis, Ganoderma applanatum, Colon Cancer, Cytotoxicity

\section{P-034 \\ EFFECT OF PHENANTROIMIDAZOLE ON CELL MIGRATION OF HUMAN COLORECTAL CARCINOMA CELLS}

Yasemin Cigdem ${ }^{1}$, Hatice Gul Batur ${ }^{1}$, Sureyya Erturk ${ }^{1}$, Kemal Bas ${ }^{1}$, Halime Seyma Akalin ${ }^{1}$, Irem Mukaddes Durmus ${ }^{1}$, Meliha Kutluca Álici², Serdar Karakurt

${ }^{1}$ Department of Biochemistry, Selcuk University, Konya, Turkey

${ }^{2}$ Department of Veterinary Medicine, Laboratory and Veterinary Health, Nigde University, Nigde, Turkey

BACKGROUND AND AIM: Colon cancer the third cause of cancer-related deaths continues to be a serious health problem worldwide. Imidazole derivatives are frequently used in many cancer studies and other biological studies. These compounds have been used as biochemical and antimicrobial markers in recent years. This study aimed to investigate the cytotoxic effects of phenantroimidazole compound and their effects on the migration abilities of the human colorectal carcinoma cells.

METHODS: The IC50 values of the phenantropimidazole compound were calculated from the sigmoidal plot of cell inhibition on human colon cancer cell (DLD-1) and human healthy colon epithelial cell (CCD-18Co) using Alamar Blue reagent. The migration abilities of the cells were determined by in vitro wound healing assay. Nf- $\kappa \mathrm{B}, \mathrm{p} 53$ (TP53) protein and gene expressions, which are effective on migration, were determined by Western Blot and qRT-PCR methods, respectively.

RESULTS: The IC50 values of phenantroimidazole in DLD-1 and CCD-18Co cells were found to be $5.5 \mu \mathrm{M}$ and $49.1 \mu \mathrm{M}$, respectively. Phenantroimidazole reduced the cell migration rate $83 \%$ compared to the control group. Phenantroimidazole increased Nf- $\kappa \mathrm{B}$ protein and gene expressions 1.5-fold, 2.5-fold, respectively. Besides p53 protein and gene expressions were upregulated 1.2-fold and 4-fold, respectively.

CONCLUSIONS: As a result, it was found that phenantroimidazole dosedependently inhibited the proliferation of DLD-1 cells and significantly $(p<0.0001)$ inhibited the migration rate of cells by upregulating $\mathrm{Nf}-\kappa \mathrm{B}$ and p53(TP53) protein and gene expressions.

Keywords: Cell Migration, Colon Cancer, Cytotoxicity, Phenanthroimidazole

\section{P-035 \\ EFFECTS OF NUTRACEUTICALS ON BREAST CANCER CELL LINE PROLIFERATION}

Goksu Sarioglu ${ }^{1}$, M. Emre Gedik ${ }^{1}$, Gurcan Gunaydin ${ }^{1}$, Ismail Celik ${ }^{2}$ ${ }^{1}$ Department of Basic Oncology, Hacettepe University, Ankara, Turkey ${ }^{2}$ Department of Medical Oncology, Hacettepe Univesity, Ankara, Turkey

BACKGROUND AND AIM: Treatments for cancer include surgery, chemotherapy, radiotherapy, hormonal therapy, and targeted therapies (such as immunotherapy, monoclonal antibody therapy). As a result of conventional treatments applied, the resistance of cancer cells to treatment is among the research topics that keep up to date. Many of the anticancer drugs damage healthy cells as well as malignant cells and show toxic effects. In order to increase the effectiveness of conventional anti-cancer treatment methods, nutraceuticals used in different cancer types are used in the treatment of metabolic and neurological diseases, especially in various inflammatory diseases. The aim of the study was to examine the effect of nutraceuticals, which are widely used in phytotherapy, on breast cancer cell line proliferation.

METHODS: HER2+ breast cancer cell line SKBR3 was grown in cell culture medium. Curcumin, sulforaphane, apocarotenal, Helichrysum arenarium, Lycopodium clavatum, Thymus serpyllum, were added to the SKBR3 at different doses and incubated for a spesified time. The effect of incubated nutraceuticals on cell proliferation was examined by MTT assay. In this way, the IC50 values of various agents were calculated and their efficacy was compared.

RESULTS: From our MTT assay and Icelligence results, we observed all of the nutraceuticals used in this study had effects on SKBR3 proliferation. We also observed that curcumin, sulforaphane, and apocarotenal has different effects on proliferation in 12 day time period which are examined by Icelligence technique. CONCLUSIONS: Six different nutraceuticals were used in this study and all of them showed various effects on SKBR3 proliferation.

Keywords: Breast cancer, nutraceuticals, MTT assay, proliferation.

\section{P-036 \\ COMPARISON OF CYTOTOXIC EFFECTS OF P. VERA ON BREAST CANCER CELL LINE WITH DIFFERENT METHODS}

Ipek Gurkebabci ${ }^{1}$, Basak Kocdor $^{2}$, Hilal Kocdor ${ }^{1}$

${ }^{1}$ DEU. Institute of Oncology, Department of Basic Oncology Izmir, Turkey

${ }^{2} \mathrm{IKCU}$, Faculty of Medicine, Department of Internal Diseases, Izmir, Turkey

BACKGROUND AND AIM: The cancer treatment agents used are toxic to normal tissues. There is a need for more potent agents that reduce the dose of the standard treatment used in breast cancer. The efficacy of P. Vera has been tested in several cell line studies around the world. MTT is the most widely used method in the literature for determining the effective concentrations of anticancer agents (although errors are observed). Commercially used WST-based methods work on the basis of evaluating the absorbance of the formazan product formed by the reduction of dehydrogenases in living cells. However, these kits are always a problem in research budgets due to their cost. The objectives of the study is a) to determine the concentrations with more stable, cheaper costs by modifying the MTT method, b) to test the efficacy of the inner bark of P. Vera as an anticancer drug candidate on a breast cancer cell line. To compare the effect of breast cancer standard treatment (Doxotaxel-DOX-) on oxidative stress.

METHODS: MDA-MB-231 breast cancer cell line was used in our study. For cell vitality tests (Cytotoxicity Analysis), Standard MTT, Modified MTT and CCK-8 (Commercial kit) methods were compared. These tests were performed to determine the cytotoxic response of cells after treatment with DOX and P.Vera. Herb; It was applied at different concentrations and as two different region extracts. Cell viability was measured after 48 and 72 hours in a microplate reader. Oxidative stress index was analyzed using Total Oxidant and Antioxidant Status kits.

RESULTS: The efficacy of the plant extract and DOX used in cytotoxicity experiments were compared. The stability of the modified MTT method was found to be statistically significantly compatible with the CCK- 8 method. It was observed that the modified MTT method had better results than the standard MTT method in all measurements. The effects on oxidative stress in combination with standard therapy were studied.

CONCLUSIONS: It has been shown that the "Modified MMT" method is superior to the "standard MTT" method in terms of reliability and stability. In the OSI index; It was determined that the use of the extract together with standard treatment increased the oxidative stress index statistically.

Keywords: P. Vera, MTT, Modified MTT, Inhibitor concentration, Total Oxidative Status 


\section{P-037 \\ EXAMINING THE BASIC FIRST AID APPLICATION KNOWLEDGE OF THE HEALTH PERSONNEL WORKING IN THE MEDICAL LABORATORY}

Nazik Yaprak ${ }^{1}$, Gulsum Abusoglu²

${ }^{1}$ Provincial Ambulance Command and Control Center Headquarters, Turkey ${ }^{2}$ Department of Medical Services and Techniques, Selcuk University Vocational School of Health Services, Turkey

BACKGROUND AND AIM: How important it is for a laboratory providing analysis service to obtain accurate and reliable results, employ qualified personnel and define employee competence, it is equally important to ensure the safety of the laboratory staff and the environment. Therefore, health personnel in medical laboratories should have sufficient knowledge and skills to apply first aid to a possible accident. Our aim is to examine the knowledge level of health personnel in medical laboratories about applying first aid in accidents that occur in the laboratory, and to make suggestions to laboratory personnels.

METHODS: Questionnaire used to collect data for research. It has been prepared consider the "Laboratory Safety Handbook" and "Basic First Aid Practices Training Book". The sample of the study consists of 62 health personnels in the Medical Laboratory. The data were collected with the "Basic First Aid Practices knowledge level questionnaire" consisting of 48 questions and three different categories. Data are calculated as a percentage of "true and false".

RESULTS: According to the answers given by the participants, they gave correct answers for $66.53 \%$ in the category of warning signs, $91.02 \%$ of definitions and general knowledge and $83.87 \%$ in the category of application information. CONCLUSIONS: It is seen that there are deficiencies in basic first aid information in general. Especially, it is envisaged that the deficiency in the category of warning signs will be eliminated by training medical laboratory personnels on the subject at certain periods by experts and improving the information.

Keywords: first aid, laboratory safety, medical personnel, medical laboratory.

\section{P-038}

\section{EVALUATION OF THE PREANALYTICAL PHASE IN TERMS OF \\ LABORATORY MEDICINE ETHICAL CODES}

Pinar Eker

Maltepe University Faculty of Medicine Central Laboratory, Istanbul, Turkey

BACKGROUND AND AIM: Current ethical approaches to general medical practice must also be included in our daily routine for laboratory medicine. Medical Ethics reports start with the Nuremberg Law in the historical development process and continue in the Geneva Declaration, Helsinki Declaration, and Belmont report. Laboratory medicine practices, as in all other medical fields, must comply with general medical ethics rules. This study will focus on what national and international laboratory ethics-oriented guidelines include, especially in terms of the preanalytical phase.

METHODS: It aims to examine whether we can apply the ethical rules of laboratory medicine in our current laboratory practices through examples. Root cause analyses of some preanalytical errors we experience in our laboratory will be examined within laboratory medicine ethical codes. Finally, the answer to what can be improvements in terms of corrective actions will be sought.

RESULTS: The phlebotomy step is critical in preanalytical phase risk management, and zero tolerance for identification errors is the basic principle. In national and international laboratory ethical codes, the sample labeling process is regulated in the patient safety priority approach to preventing identification errors. Tubes that do not contain patient identifiable information as described in the guidelines in today's preanalytical processes pose a risk in patient safety. LIMS systems cannot help the laboratory specialist to implement patient safety and ethical codes fully. There is a risk of sample traceability and stability management

CONCLUSIONS: National and international hospital quality management systems give the first-degree follow-up and improvement responsibility of the preanalytical process to laboratory specialists. On the other hand, in today's global laboratory management models, preanalytical error management will only be possible with error-free management, especially in the field of "informational technology management," where the laboratory specialist is not fully effective and competent. At this point, health policymakers and laboratory specialists may re-examine the laboratory ethical codes and perhaps seek new trajectories, enabling us to achieve preanalytical process management with patient safety. Keywords: preanalytical phase,ethical codes,safe phlebotomy

\section{P-039 \\ INVESTIGATION OF REQUESTING PROFILE OF THYROID}

FUNCTION TESTS IN DISTRICT STATE HOSPITAL

Ebru Yaprak

Turhal Public Hospital, Medical Biochemistry, Tokat, Turkey

BACKGROUND AND AIM: Thyroid function tests (TFT) are the most frequently requested endocrine tests from clinical laboratories. The most frequently requested tests in TFT are serum thyroid stimulating hormone (TSH), free triiodothyronine (fT3) and free tetraiodothyronine (fT4) tests. It is aimed to evaluate the test request tendencies applied by the clinics before the decision to switch to reflex testing for TFT in Turhal State Hospital

METHODS: The tests requested in the 6-month period between 01.01.2021 and 30.06.2021 in outpatients admitted to the hospital were taken from the automation system. Among these tests, TSH, fT3 and fT4 were examined and the simultaneous request rates of these tests were analyzed.

RESULTS: In this period, a total of 29083 thyroid function tests were requested from 11627 patients, and only TSH in $1401(12 \%)$ patients, TSH and free T4 in $2996(25.8 \%)$ patients, and TSH, free T3 and free T4 together in $7230(62.2 \%)$ patients. has been requested.

CONCLUSIONS: Although the guidelines recommend the use of TSH test as a first step test for thyroid diseases, it has been seen that the algorithms are not taken into account sufficiently by the clinics. It is seen that this situation may be caused by clinical habits, as well as the high density of outpatients and if the algorithm is applied, it may be necessary to draw blood from the patient again and there is a concern about time loss. In our hospital, reflex testing has been planned because of both preventing unnecessary test requests and contributing to cost-effectiveness analysis.

Keywords: Cost-effectiveness analysis, Reflex test, Thyroid function tests

\section{P-040 \\ ANALYSIS OF MITOTIC FUNCTIONS OF ENSA AND ARPP19 PROTEINS BY MOLECULAR GENETIC TOOLS}

M. Kasim Diril ${ }^{1}$, Mehmet Erguven ${ }^{2}$

${ }^{1}$ Izmir Biomedicine and Genome Centre, Izmir, Turkey; Izmir International Biomedicine and Genome Institute, Dokuz Eylul University, Izmir, Turkey; Department of Medical Biology, Basic Medical Sciences, Faculty of Medicine, Dokuz Eylul University, Izmir, Turkey

2Izmir Biomedicine and Genome Centre, Izmir, Turkey; Izmir International Biomedicine and Genome Institute, Dokuz Eylul University, Izmir, Turkey

BACKGROUND AND AIM: Cdk1 kinase phosphorylates many protein substrates during mitosis to keep the cell in a mitotic state. Protein phosphatase 2A (PP2A) which reverses protein phosphorylations has to be temporarily inactivated during mitosis. To this end, Cdk1 phosphorylates and activates Mastl kinase, which, in turn, phosphorylates and activates ENSA and Arpp19 proteins. Either of these two phosphoproteins can bind to PP2A-B552 complex (PP2A isoform active in mitosis) and inhibit its enzymatic activity. As a result, the phosphorylations on mitotic proteins persist through mitosis. How mitotic division progresses, whether cells can divide correctly in the absence of ENSA and Arpp19, or whether overexpression of these proteins can rescue Mastl deficiency in Mastl KO cells are open questions waiting to be answered.

METHODS: We aimed to investigate the mitotic division and cellular proliferation in primary mouse embryonic fibroblast (MEF) cells where Mastl gene can be conditionally knocked out via the Cre/Lox system, after overexpression of the predominant Arpp19 protein or after its depletion via shRNA mediated knockdown. Lentiviral and retroviral expression systems were used to get Arpp19 gene overexpressed or silenced. Subsequently, clonal cell lines were isolated and analysed.

RESULTS: Silencing of Arpp19 expression inhibited cellular proliferation. Overexpression of WT or phosphomimetic forms of Arpp19 was not sufficient to rescue the effects of Mastl depletion.

CONCLUSIONS: Primary MEFs need either of ENSA or Arpp19 inhibitory proteins to complete mitosis correctly. The fact that Mastl knockout cells cannot complete mitotic division even after high level expression of Arpp19 suggests, Mastl may have other roles unrelated to Arpp19.

Keywords: Cell cycle, mitosis, Mastl, Arpp19, ENSA, PP2A

\section{P-041}

\section{NONDELETIONAL ALPHA THALASSEMIA IN CUKUROVA REGION}

Yusuf Dogus, Mehmet Akif Curuk

Department of Medical Biochemistry, Faculty of Medicine, Cukurova

University, Adana, Turkey

BACKGROUND AND AIM: Alpha thalassemia is a genetic disease characterized by decreased or definite absence of alpha globin chain synthesi in the hemoglobin chain. Alpha globin chains are synthesized by the $\alpha 1$ and $\alpha 2$ genes in the short arm of chromosome 16. Each allele has two alpha globin $(\alpha 1$ ve $\alpha 2)$ genes. A human has four alpha genes $(\alpha \alpha / \alpha \alpha)$. The $\alpha$-thalassemias usually result from deletions involving the $\alpha$-globin genes, less commonly they are due to point mutations. Tree different large deletions $[\alpha$-thal-1(--/ $\alpha \alpha:-17.4 \mathrm{~kb},-20.5$ $\mathrm{kb}$ and $-26.5 \mathrm{~kb})]$ and two small deletion[ $\alpha$-thal $-2(-\alpha / \alpha \alpha:-3.7 \mathrm{~kb}$ and $-4.2 \mathrm{~kb})]$ were carecterized in Turkey. In addition, there are two different PolyA mutations (PA1:AATAAA/AATAAG and PA2:AATAAA/AATGAA) on the $\alpha 2$-globin gene $(\alpha \alpha / \alpha T \alpha)$ and a $5 n t$ deletion. There is also the Hb Adana point mutation on the $\alpha 1$ globin gene. In our country, ten different combinations of $\alpha$-thal-1 and $\alpha$-thal-2 (-$/-\alpha)$ or $\mathrm{HbH}$ genotype with point mutations (--/ $\alpha \mathrm{T} \alpha$ or $--/ \alpha \alpha \mathrm{T}$ ) were determined. People with silent and heavy alpha gene deletions are completely healthy: But, $\mathrm{HbH}$ disease occurs in children with both mutant alleles by marrying those 
carrying these point mutations $(\alpha 5 n t \alpha / \alpha 5 n t \alpha)$ and $(\alpha$ PolyA $\alpha / \alpha$ PolyA $\alpha)$. HbH $(\beta 4)$ is found to have an unstable structure in the blood of individuals with only one intact alpha gene $(--/ \alpha T \alpha)$ carrying $\alpha$-thal-1 and point mutations together. The aim of this study is evaluation of complete blood counts of individuals with nondeletional homozygous $\mathrm{HbH}$.

METHODS: DNA was isolated from the blood samples of patients with severe anemia $(7.7<\mathrm{Hb}<9.2,60<\mathrm{MCV}<70)$ who applied to Cukurova University, Balcali Hospital and showed $\mathrm{Hb} \mathrm{H}$ band as a result of hemoglobin electrophoresis. Point mutations were determined by the ARMS method.

RESULTS: In the study, as homozygous, two different point mutations were found in 7 patients $(\alpha 5 \mathrm{nt} \alpha / \alpha 5 \mathrm{nt} \alpha)$, and in 4 patients ( $\alpha$ PolyA $\alpha / \alpha$ PolyA $\alpha$ ). It was determined that one patient $(--20,5 / \alpha 5 n t \alpha)$ had large gen deletion and point mutations together.

CONCLUSIONS: It was determined that the complete blood count of the patient with the combination $(--20,5 / \alpha 5 n t \alpha)$ was better than the homozygous PolyA and 5 nt mutations.

Keywords: $\mathrm{HbH}$, Alpha Thalassemia, Point mutation

\section{P-042}

RECOMBINANT APPROACHES AND OPTIMIZATION OF

EXPRESSION CONDITIONS FOR HIGH YIELD, SOLUBLE E3

ENZYME OF HUMAN ISGYlation SYSTEM (HSHERC5) FOR STRUCTURAL STUDIES

Oktay Gocenler $^{1}$, Cansu Yenici ${ }^{1}$, Jennifer M. Klein ${ }^{2}$, Hasan Demirci ${ }^{3}$,

Arthur L. Haas ${ }^{2}$, Cagdas $\mathrm{Dag}^{4}$

${ }^{1}$ Department of Molecular Biology and Genetics, Koc University, Istanbul

${ }^{2}$ Department of Biochemistry and Molecular Biology, School of Medicine,

Louisiana State University, New Orleans, Louisiana

${ }^{3}$ Department of Molecular Biology and Genetics, Koc University, Istanbul;

Stanford PULSE Institute, SLAC National Laboratory, Menlo Park, CA, USA

${ }^{4}$ Department of Molecular Biology and Genetics, Koc University, Istanbul,

Turkey; Koc University, Nanofabrication and Nanocharacterization Center for

Scientific and Technological Advanced Research (n2STAR), Istanbul, Turkey;

Koc University Isbank Center for Infectious Diseases (KUISCID), Istanbul,

Turkey

BACKGROUND AND AIM: The first line of defense against viral infection is implemented by the innate immune system regulated with interferons. One of the most important immune responses is utilized by type 1 interferons (IFN-1) to allow an antiviral response called ISGylation post translational modification system. Interferon-stimulated gene-15 (ISG15) is a protein with two Ubiquitinlike-domains (UBL) linked by a short peptide chain and it's the main protein of ISGylation system. Similar to Ubiquitin, ISG15 is ligated to the target proteins with a series of E1, E2 and E3 enzymes respectively. E1 enzyme is named as Uba7, E2 enzyme as UbcH8 and E3 enzyme as HERC5. It was found that HERC5 associates with ribosomes and ISGylation is executes together with translation. Due to its critical role in antiviral immunity, HERC5 is an important drug target for boosting innate antiviral immunity. However, protein structure of HERC5 is still not available, which makes it difficult to understand its relation with viral proteins and ribosomes. A High amount and purity of soluble protein is needed for structural studies. Obtaining soluble and high yield and amount of protein is one of the biggest challenges.

METHODS: With this aim, different constructs of the protein were tested and a solubility tag was used. In addition, optimization of expression conditions are carried out.

RESULTS: Within the scope of the study, it was observed that the GST tag increased the solubility but could not stop the degradation of the protein. The first 155 amino acids were omitted from the protein sequence to prevent protein degradation. Besides, temperature, medium and expression rate were optimized. CONCLUSIONS: The first 155 amino acids of the protein are thought to have a key role in ribosome binding. Since the protein cannot escape this binding, it is thought to be degraded after cell lysis. we aim to solve the structure of the protein soon.

Keywords: HERC5, ISGylation, post translational modifications, antiviral response

\section{P-043 \\ OPTIMIZATION STRATEGIES FOR IMPROVING SOLUBLE EXPRESSION OF SARS-COV-2 S1 PROTEIN USING SUMO-FUSION TECHNOLOGY}

Melike Yagmur Unal $^{1}$, Kubra Acikalin Coskun ${ }^{2}$, Hasan Umit Ozturk ${ }^{1}$ ${ }^{1}$ Genetic Engineering and Biotechnology Institute, Marmara Research Center, TUBITAK, , Turkey

${ }^{2}$ Istanbul Aydin University, Istanbul, Turkey

BACKGROUND AND AIM: E. coli are widely used for recombinant protein development, due to its low cost, ease of manipulation, and availability of well established molecular tools and techniques. Due to a lack of sophisticated machinery to undertake posttranslational modifications, the E. coli bacterial culture is limited in its ability to express more complex proteins, resulting in low solubility of the protein of interest that is generated as inclusion bodies. Although we were able to produce the recombinant SARS-CoV-2 -S1 protein at high expression levels in our earlier investigation, we were also able to obtain nearly the whole protein as inclusion body. To overcome this problem, different solubility strategies have been tried. In this study, we developed an E.coli expression strategy based on the expression of the S1 protein as a fusion of SUMO fusion protein.

METHODS: The DNA sequence of S1 protein was cloned into the pET SUMO expression vector, resulting in a construct expressing a N-terminal tag SUMO fusion protein. To achieve the high-level expression of S1, small scale expression conditions were optimized in E. coli BL21 (DE3) containing pET SUMO-S1 with different induction temperatures, times and IPTG concentrations. Additionally, different medium was also tested for the expression of S1 protein. For each parameter, solubility and expression of cell lysates from uninduced and induced cultures, plus the soluble and insoluble fractions from induced cultures were analyzed by SDS-PAGE and Western Blot.

RESULTS: SDS-PAGE and Western Blot analysis showed the presence of a $\sim 83 \mathrm{kDa}$ recombinant fusion protein. The maximum level of expression of the recombinant protein was observed at 30 囚, $4 \mathrm{~h}$ after induction with $0,55 \mathrm{mM}$ IPTG

CONCLUSIONS: This study showed that the use of SUMO fusion tag partially increases the production of $\mathrm{S} 1$ protein in the form of soluble fractions and optimization studies continue.

Keywords: Expression, Spike Protein, SUMO Fusion Tag,

\section{P-044 \\ DEVELOPMENT OF DUAL-VALIDATION VOLTAMMETRIC/ IMPEDIMETRIC APTAMER-BASED BIOSENSOR FOR DETECTION OF CROHN'S DISEASE VIA CALPROTECTIN}

Cigdem Gozde Aslan ${ }^{1}$, Zihni Onur Uygun ${ }^{2}$, Hilmiye Deniz Ertugrul Uygun ${ }^{3}$, Nalan Gulsen Unal ${ }^{4}$, Yasemin Akcay ${ }^{1}$

${ }^{1}$ Department of Medical Biochemistry, Faculty of Medicine, Ege University, Izmir, Turkey

${ }^{2}$ Department of Medical Biochemistry, Faculty of Medicine, Kafkas University, Kars, Turkey

${ }^{3}$ Center for Fabrication and Application of Electronic Materials, Dokuz Eylul University, Izmir, Turkey

${ }^{4}$ Department of Gastroenterology, Faculty of Medicine, Ege University, Izmir, Turkey

BACKGROUND AND AIM: Inflammatory bowel diseases (IBD) are defined as inflammatory diseases in the gastrointestinal tract and has great clinical importance. In the absence of any treatment, it is important to follow up the chronic remission and attack states. Among these diseases, Crohn's subgroup constitutes the disease, and the disease can be followed by the determination of fecal calprotectin.

METHODS: Biyosensor, sistamin ve avidin-biotin etkilesimi ile altin nanoparcacik uzerinde hareketsiz hale getirilen aptamer ile gelistirildi. Biyosensor, yanal akis testi (LFA) kadar dogru sonuclar verebilir. Olcum suresi kronoimpedimetrik olcum ile 900 saniye olarak belirlendi ve biyosensor lateral akis kalprotektin testi ile karsilastirildi.

RESULTS: The detection range of the biosensor was determined as 20-800 $\mu \mathrm{g} / \mathrm{g}$, and LOD and LOQ 7.73 and 23.42 for linear scanning voltammetry (LSV) and 5.57 and 16.89 for electrochemical impedance spectroscopy (EIS).

CONCLUSIONS: As a result, the calprotectin biosensor designed based on aptamer is very suitable for measuring this biomarker used in Crohn's disease. Keywords: inflammatory bowel diseases, calprotectin, biosensor, aptamer

\section{P-045 \\ EVALUATION OF FRESHNESS, NATURALNESS AND QUALITY OF HONEY PRODUCED IN DIFFERENT REGIONS OF TURKEY}

Fatih Ozcelik, Ali Imran Destan

The University of Health Sciences Turkey, Hamidiye Faculty of Medicine,

Department of Medical Biochemistry, Istanbul, Turkey

BACKGROUND AND AIM: In this study, the amino acid and carbohydrate profiles, invertase enzyme activity (IEA) and 5-Hydroxymethylfurfural (HMF) levels of honey produced in different regions of Turkey were measured, thereby their compliance with the Turkish Food Codex in terms of freshness, naturalness and quality was investigated.

METHODS: In October 2018, 10 types of honey obtained from different regions of Turkey were included in the evaluation. All honeys were kept at 20-25 oC in a moisture-free and dark environment until they were analyzed. Amino acid profiles of honeys at $0,1,4$ and 7 months were measured with GC-MS, carbohydrate profiles and HMF levels were measured with HPLC and IEA levels were measured with the spectrophotometer. The results obtained were compared with the safe consumable limit values determined by the Turkish Food Codex RESULTS: Approximately $48 \%$ of the total amino acids in all honeys at the 0 th month consisted of proline. It was determined that proline and phenylalanine levels, which are quality indicators of aging honey, decreased significantly at the 
end of the 7th month, whereas glycine levels increased over time $(\mathrm{P}<0.01)$. It was determined that HMF concentrations increased proportionally with the storage time, while IEA decreased $(\mathrm{P}<0.01)$. In addition, HMF concentrations were found to be moderately negatively correlated with valine, asparagine and fructose/ glucose ratio (Sp r: -0.422 , Sp r: -0.428 Sp r: -0.519 ; $\mathrm{P}<0.01$, respectively).

CONCLUSIONS: The high proline, phenyl alanine and IEA values of honey as well as the low HMF levels should be used together as an indicator of freshness and naturalness, which are quality elements. In addition, the increase of toxic components such as HMF in aging honey; shows that honey should be consumed without long-term storage.

Keywords: Honey, Fructose, 5-Hydroxymethylfurfural, Proline

\section{P-046 \\ EXAMINING THE NUTRITION STATUS OF SPINAL MUSCULAR ATROPHY PATIENTS AND ESTABLISHING NUTRITIONAL APPROACHES FOR THE SUBTYPES OF THE DISEASE}

Edanur Usta, Sultan Demiral, Tugba Hakverdi, Ayse Tugce Karagedik, Oyku Gonul Geyik

Istinye University, Faculty of Health Sciences, Nutrition and Dietetics

Department, Istanbul / TURKEY

BACKGROUND AND AIM: Spinal muscular atrophy (SMA), a neurodegenerative disease, is a cause of premature death. Although nutritional complications and digestive system problems are frequently encountered, a special nutrition plan cannot be applied due to lack of nutritional studies in SMA. In this study, we aimed to establish a nutritional approach to SMA and to reduce complications related to nutrition.

METHODS: A total of 8 patients, aged 0-22, registered to SMADER and diagnosed with SMA Type 1,2 and 3 participated in the study. Data were collected between March2021-May2021 through an online questionnaire. The answers with negative effects to the patient were scored as 0 , neutral effects as 1 , and the positive effects as $1-5$ points

RESULTS: Malnutrition a decrease in oral nutrition due to reasons such as aspiration and dysphagia was observed in $7(87.5 \%)$ of the participants. One SMA patient without malnutrition, was also found to be only participant followed by a dietitian.

CONCLUSIONS: The decrease in oral food intake is thought to cause nutrient requirements not to be met and thus malnutrition. However, ketoacidosis, which is generally seen as a result of inadequate nutritional intake, was not observed in our patients, which could be that although the Type1 SMA patients in the study were malnourished, they did not have a carbohydrate deficiency that would cause ketoacidosis. As the result of the study, we showed that adequate carbohydrate and protein intake is of extra importance for SMA patients, and detailed studies are needed to elucidate the factors cause malnutrition and prevent reaching the targeted energy requirement.

Keywords: Spinal muscular atrophy, ketoacidosis, malnutrition, nutrition

\section{P-047 \\ HESPERIDIN ATTENUATES SODIUM SELENITE-INDUCED CATARACTOGENESIS IN WISTAR RATS}

Emel Serdaroglu Kasikci ${ }^{1}$, Burcu Cevreli ${ }^{2}$, Ibrahim Sahbaz ${ }^{3}$, Aleyna Oztas ${ }^{1}$, Korkut Furkan Sahin ${ }^{4}$, Tayfun Gozler ${ }^{2}$, Muhsin Konuk ${ }^{1}$

${ }^{1}$ Uskudar University, Faculty of Engineering and Natural Sciences, Department of Molecular Biology and Genetics, Istanbul, Turkey

${ }^{2}$ Uskudar University, Neuropsychopharmacology Research and Application

Center, Istanbul, Turkey

${ }^{3}$ Uskudar University, Faculty of Medicine, Department of Opticianry, Istanbul,

Turkey

${ }^{4}$ Gebze Technical University, Institute of Natural and Applied Sciences,

Molecular Biology and Genetics, Kocaeli, Turkey

BACKGROUND AND AIM: Cataract, known as opacification of the lens in the eye, is one of the causes of blindness worldwide. The aim of this study was to investigate the potential protective effects of hesperidin (HES) in an experimental cataract model with sodium selenite $(\mathrm{Na} 2 \mathrm{SeO} 3)$ in male Wistar rats.

METHODS: Thirty-two Wistar-albino rat pups were assigned into four groups. Group 1: Only saline $(0.9 \% \mathrm{NaCl})$ was administered by subcutaneously (s.c) Group 2: Nuclear cataract was produced single dose $20 \mu \mathrm{mol} / \mathrm{kg}$ s.c. Na2SeO3 on the postnatal 10th day, Group 3: HES was dissolved in saline solution and $100 \mathrm{mg} / \mathrm{kg}$ was administered by oral gavage for 4 weeks. Group 4: Na2SeO3 $(20 \mu \mathrm{mol} / \mathrm{kg})$ was given s.c. and HES $(100 \mathrm{mg} / \mathrm{kg})$ was given by oral gavage. The reduced glutathione (GSH), malondialdehyde (MDA) and total antioxidant status (TAS) in lens supernatants were measured spectrophotometrically. Data were analyzed using the SPSS software package. One-way ANOVAs followed by post-hoc Bonferroni tests were used for statistical analysis $(\mathrm{p}<0.05)$.

RESULTS: It was observed that GSH and TAS levels decreased in the Na2SeO3 group compared to the control group, while MDA levels increased significantly. While no significant change was observed in GSH and TAS levels in the HES group compared to the control group, MDA levels decreased significantly. At the same time, GSH and TAS levels were significantly increased in the
$\mathrm{Na} 2 \mathrm{SeO} 3+\mathrm{HES}$ group compared to the $\mathrm{Na} 2 \mathrm{SeO} 3$ group, while MDA levels were significantly decreased.

CONCLUSIONS: Although it was observed in our study that hesperidin had positive effects on MDA levels, which is a marker of oxidative damage, in the cataract model, further studies on hesperidin are needed.

Keywords: Cataract, Lens, Hesperidin, Oxidative damage, Sodium selenite

\section{P-048 \\ DETERMINATION OF OXIDATIVE DAMAGE CAUSED BY METHOTREXATE AND 5-FLUOROURACIL IN LIVER, HEART AND KIDNEY TISSUES IN RATS}

Emine Atakisi, Ebru Ozgun, Lale Besli

Kafkas University Faculty of Veterinary Medicine Department of Biochemistry, Kars, Turkey

INTRODUCTION AND AIM:Fluorourosil (5-FU) is used as a chemotherapy drug in many types of cancer and is a pyrimidine analog. Methotrexate (MTX) is used as a chemotherapeutic agent in many diseases from autoimmune system diseases to cancer. In addition to its therapeutic properties, it causes damage to organs such as liver and kidney. In this study, it was aimed to determine the oxidative damage caused by Sprague Dawley rats in liver, kidney and heart tissue. METHOD:In our study, 15 2-month-old male Sprague Dawley rats were divided into 3 groups. Group 1: Control group, Group 2: MTX group, Group 3: 5-FU group. One day after the application, the rats were anesthetized and liver, kidney and heart tissues were removed surgically after cervical dislocation. The levels of malondialdehyde (MDA), which is a marker of lipid peroxidation, nitric oxide (NO), a free radical, and reduced glutathione (GSH), which is an endogenous antioxidant, were measured in these tissues. Significantly low, MDA and NO levels were found to be significantly higher in the FU groups. Similarly, kidney GSH levels were significantly lower in the MTX and 5-FU groups compared to the control group, MDA was higher in both groups, and NO was higher in only the MTX group. GSH levels in heart tissue were found to be significantly lower in MTX and 5-FU groups, MDA was significantly higher, and NO was significantly higher only in the 5-FU group compared to the control group.

DISCUSSION AND CONCLUSION:Conclusively, MTX and 5-FU It has been concluded that FU may cause oxidative damage in kidney, liver and heart tissue and cause changes in oxidative damage markers and antioxidant levels. Keywords: Malondialdehyde, Methotrexate, Nitric Oxide, Oxidative Damage, Reduced Glutathione

\section{P-049 \\ OXIDATIVE DNA DAMAGE, GLUTATHIONE REDOX STATUS AND THEIR RELATION WITH DNA REPAIR GENE HOGG1 POLYMORPHISM IN HYPERTHYROIDISM}

Yildiz Dincer ${ }^{1}$, Caglayan Akkaya Engin ${ }^{2}$, Serkan Teksoz ${ }^{3}$, Ali Ata Tuz ${ }^{4}$, Gizem Erdogan ${ }^{5}$, Mehmet Guven ${ }^{5}$, Duygu Vardagli ${ }^{2}$, Emel Zengin ${ }^{6}$

${ }^{1}$ Department of Medical Biochemistry, Istanbul University-Cerrahpasa, Istanbul, Turkey

${ }^{2}$ Department of Medical Biochemistry, Istanbul University-Cerrahpasa,

Istanbul, Turkey; Program of Medical Laboratory Techniques, Istanbul Esenyurt University, Istanbul, Turkey

${ }^{3}$ Department of General Surgery, Istanbul University-Cerrahpasa, Istanbul, Turkey

${ }^{4}$ Cerrahpasa Medical School, Istanbul University-Cerrahpasa, Istanbul, Turkey

${ }^{5}$ Department of Medical Biology, Istanbul University-Cerrahpasa, Istanbul, Turkey

${ }^{6}$ Department of Medical Biochemistry, Istanbul University-Cerrahpasa, Istanbul, Turkey; Medical Biochemistry Laboratory, Istanbul Hospital, Baskent University, Istanbul, Turkey

BACKGROUND AND AIM: Hyperthyroidism is associated with oxidative stress. Oxidative DNA damage may contribute to the development of some complications in patients with hyperthyroidism. DNA repair protein, human 8-oxo-deoxyguanosine DNA glycosylase 1 (hOGG1), is the enzyme which is responsible for the removal of oxidative DNA damage. This study aims is to examine the role of hOGG1 Ser326Cys polymorphism on DNA strand breaks, oxidized purines, urinary $8-\mathrm{OHdG}$ level and glutathione redox status (GSH/ GSSG ratio) in patients with hyperthyroidism.

METHODS: The study included 58 patients undergoing total thyroidectomy due to hyperthyroidism and 65 volunteers as control. DNA strand breaks and oxidized purines in lymphocytes were detected by comet assay, erythrocyte GSH and GSSG levels and urinary $8-\mathrm{OHdG}$ level were measured by spectrophotometric method and enzyme-linked immunoassay (ELISA), respectively. hOGG1 Ser326Cys genotyping was performed by polymerase chain reaction-restriction fragment length polymorphism assay (PCR-RFLP).

RESULTS: DNA strand breaks and oxidized purines were higher in the patients with hyperthyroidism than those in the control cases. There are no significant changes in GSH/GSSG ratio and urinary 8-OHdG. No significant difference was found between cases carrying Ser/Ser genotype and cases carrying Ser/ $\mathrm{Cys}+\mathrm{Cys} / \mathrm{Cys}$ genotype for tested parameters in patients with hyperthyroidism. 
CONCLUSIONS: Oxidative DNA damage, in the term of strand breaks and oxidized purines, is increased in patients with hyperthyroidism but oxidative DNA damage status is irrelevant with hOGG1 Ser326Cys polymorphism in these patients.

Keywords: Antioxidant defence, Hypertiroidism, hOGG1, Ser326Cys polymorphism

\section{P-050
EFFECTS OF OXIDATIVE STRESS-RELATED BIOCHEMICAL MARKERS ON DISEASE PROCESS IN PATIENTS WITH ADVANCED LUMBAR SPONDYLOLISTHESIS}

Gokmen Reyhanli ${ }^{1}$, Ummuhani Ozel Turkcu², Arsal Acarbas ${ }^{1}$, Muslum Gok $^{2}$, Derya Burcu Hazer Rosberg ${ }^{1}$

${ }^{1}$ Mugla Sitki Kocman University, Faculty of Medicine, Department of

Neurosurgery, Mugla, Turkey

${ }^{2}$ Mugla Sitki Kocman University, Faculty of Medicine, Department of Medical Biochemistry, Mugla, Turkey

BACKGROUND AND AIM: One of the most common complaints in clinical practice is low back pain and accompanying spinal degenerative diseases. Oxidative stress is assumed to play an important role in the degenerative process. In this study, the oxidative stress level in the interspinous ligament tissue of patients with spondylolisthesis and the effects of related biochemical markers on the patient's clinic were investigated.

METHODS: Patients with degenerative spondylolisthesis, lumbar spinal stenosis, and spinal trauma under the age of 40, who applied to the Neurosurgery clinic at Mugla Sitki Kocman University Training and Research Hospital and diagnosed with surgery were included in this study. Interspinous ligament tissue samples, which were removed during surgical decompression and turned into medical waste, were used from all patients whose written consent was obtained. These patients were divided into three groups as lumbar spondylolisthesis (LSL) patients $(n=14)$, lumbar spinal stenosis (LSDK) $(n=14)$ and young trauma patients $(n=10)$. A power analysis of the number of patients yielded an $80 \%$ confidence level and a 5\% margin of error. Superoxide dismutase, total sulfhydryl, and AOPP levels were determined using a spectrophotometric method in the collected interspinous ligament samples.

RESULTS: In our study, SOD enzyme $(\mathrm{p}=0.496)$ activity, total sulfhydryl $(p=0.260)$ and AOPP $(p=0.365)$ levels were not found statistically significant between the groups. Although there was no statistically significant difference, when we analyzed the SOD values, it was found that the lowest value was in the trauma group and the highest value was in the LSL group. The total sulfhydryl values also showed that the LSDK group had the highest values and the trauma group had the lowest. While AOPP levels were highest in the trauma group, they were the lowest in LSL patients.

CONCLUSIONS: In this study, oxidative stress markers were studied for the first time in interspinous ligament samples. Although results were not statistically significant; The high SOD and total sulfhydryl values as well as the low AOPP values, implying that it may play a protective role in the ongoing inflammatory process in these degenerative diseases. Further studies in a large patient group are needed to understand the effects of oxidative stress on lumbar spondylolisthesis. Keywords: AOPP, interspinous ligament, lumbar spinal stenosis, lumbar spondylolisthesis, SOD, total sulfhydryl

\section{P-051 \\ INVESTIGATION OF YKL-40/CHITINASE 3-LIKE PROTEIN 1 AND THIOL-DISULFIDE HOMEOSTASIS IN SERA OF CHILDHOOD CHRONIC KIDNEY PATIENTS}

Melek Sena Tarakcioglu ${ }^{1}$, Zeynep Gokturk Erdogan ${ }^{2}$, Beltinge Demircioglu ${ }^{2}$, Hasan Ulusal ${ }^{1}$, Ayse Balat ${ }^{3}$, Seyithan Taysi

${ }^{1}$ Gaziantep University, Department of Medical Biochemistry, Gaziantep, Turkey ${ }^{2}$ Gaziantep University Faculty of Medicine, Department of Pediatric Nephrology, Gaziantep, Turkey

${ }^{3}$ Gaziantep University Faculty of Medicine, Department of Pediatric

Nephrology and Rheumatology, Gaziantep, Turkey

BACKGROUND AND AIM: Chronic kidney disease (CKD) refers to a condition associated with irreversible kidney damage that can progress to end-stage renal disease (ESRD). In this study, we aimed to measure human chitinase-3-like Protein 1 (YKL-40), oxidant/antioxidant status and thiol-disulfide homeostasis parameters in the sera of childhood chronic kidney patients and to investigate whether there is a relationship between the severity of the disease.

METHODS: 25 peritoneal dialysis (PD) patients, 10 hemodialysis (HD) patients, 25 compensated chronic kidney disease (CKD) and 20 healthy individuals were included in the study as the control group. Serum YKL-40 levels were measured by ELISA method in the patient and control groups. The status of native thiol, total thiol, total antioxidant and total oxide were measured in an autoanalyzer (Beckman Coulter AU*480) using commercial kits.

RESULTS: Creatinine, GFR, total oxidant status (TOS), total antioxidant status (TAS), oxidative stress index (OSI), Native thiol (Nthiol), total thiol (Tthiol), Disulfite, Disulfite/Nthiol, Disulfite/Tthiol, Nthiol When /Tthiol and YKL-40 values were found to be statistically significantly higher when compared with the control group, Nthiol, Tthiol, Disulfide and YKL-40 levels were found to be significantly lower $(p<0.05)$. In addition, significant negative and positive correlations were detected between the parameters in each group.

CONCLUSIONS: Our results suggest that the oxidant status increased in the patient groups and the addition of antioxidant substances would be beneficial in addition to the treatment applied.

Keywords: Childhood Chronic Kidney Disease, Dialysis, Oxidative Stress, Thiol Disulfide, YKL-40

\section{P-052 \\ INVESTIGATION OF OXIDATIVE STRESS METABOLISM IN CENTRAL NERVOUS SYSTEM AND PERIPHERAL TISSUE IN SOD1G93A ALS RATS}

Duygu Aydemir ${ }^{1}$, Ayse Nazli Basak ${ }^{2}$, Nuriye Nuray Ulusu

${ }^{1}$ Koc University Medical School Medical Biochemistry, Istanbul, Turkey ${ }^{2}$ Koc University Research Center for Translational Medicine (KUTTAM), Sariyer, 34450, Istanbul, Turkey

BACKGROUND AND AIM: ALS is the most common motor neuron disease and incidence of the disease is increasing worldwide. Since there is no treatment for ALS, targeting therapy approaches are urgently required to cure people with ALS. In our study we have investigated oxidative stress metabolism in the CNS and peripheral tissue as possible targeted therapy approach.

METHODS: SOD1G93A mutated male rats were divided into 5 groups based on the age and each group divided into two subgroups according to the mutation as wild type and G93A mutated. Tissues were collected after sacrification and oxidative stress enzymes were measured in the tissues.

RESULTS: Glucose-6 phosphate dehyrogenase (G6PD) and 6-phodphoglucanate dehydrogenase (6-PGD) enzymes were decreased in the liver and brain tissues of mutated rats compared to the wild type rats. On the other hand, glutathione reductase (GR) enzyme activities decreased in the mutated rats in the brain and liver tissues compared to the wild type rats, where glutathione s-trabsferase activity (GST) increased in the mutated rats. Our data showed that oxidative stress metabolism impaired in the brain and liver tissues of the SOD1 G93A mutated rats.

CONCLUSIONS: Our data showed that oxidative stress metabolism is impaired in the SOD1 G93A mutated rats compared to the wild type rats, that can be used for the possible targeted therapy approaches to treat people with ALS.

Keywords: ALS, oxidative stress, liver, brain

\section{P-053 \\ EVALUATION OF THE RELATIONSHIP BETWEEN OXIDATIVE STRESS AND RAFTLIN LEVELS IN WOMEN WITH POSTMENOPAUSAL OSTEOPOROSIS}

Meltem Gungor ${ }^{1}$, Ergul Belge Kurutas ${ }^{2}$

${ }^{1}$ SANKO University, Faculty of Medicine, Department of Medical Biochemistry, Gaziantep, Turkey

${ }^{2}$ Kahramanmaras Sutcu Imam University, Faculty of Medicine, Department of Medical Biochemistry, Kahramanmaras, Turkey

BACKGROUND AND AIM: Postmenopausal osteoporosis is a disease in which the tendency to fracture in bones increases due to decreased bone mineral density. Oxidative stress is an important risk factor for osteoporosis. Raftlin is known to play a role in the vascular endothelial response in postmenopausal osteoporosis patients. There are studies on antioxidant enzyme activities and oxidative stress markers in the literature, but there is no study comparing the levels of Raftlin with oxidative stress levels. The aim of this study is to compare oxidative stress, antioxidant response and Raftlin levels between postmenopausal osteoporosis patients and the control group.

METHODS: Postmenopausal women with or without osteoporosis (n: 40) and healthy controls (n:30) who applied to the Gynecology and Obstetrics Clinic of KSU Faculty of Medicine between January 2019 and September 2020 were included in our study. Bone mineral density, routine laboratory tests, 25-hydroxyvitamin D3, raftlin, catalase (CAT), superoxide dismutase (SOD) and malondialdehyde (MDA) levels were measured in our study groups. CAT, SOD and MDA levels were measured by spectrophotometric method, Raftlin levels were measured with a commercial ELISA kit.

RESULTS: It was determined that Raftlin and MDA levels were significantly increased in both postmenopausal groups compared to the control, while SOD and CAT were significantly decreased $(p<0,05)$. The lowest antioxidant enzyme activity and the highest MDA and raftlin levels were detected in postmenopausa osteoporosis patients $(\mathrm{p}<0,05)$. Moreover, a positive correlation was found between raftlin levels and MDA levels $(r=0.395, \mathrm{p}<0.001)$.

CONCLUSIONS: These results show a relationship between osteoporosis and oxidative stress. It is thought that free oxygen radical production increases excessively in both postmenopausal groups and accordingly, antioxidant enzyme activities decrease. It is also thought that MDA and raftlin levels increase. In addition, Raftlin, a new marker, may be an important parameter in determining the prognostic process of groups with postmenopausal osteoporosis. Keywords: Postmenopausal, Osteoporosis, Oxidative Stress, Raftlin 


\section{P-054 / ANTIOXIDANT SYSTEM AND SOME BLOOD PARAMETERS IN RABBITS WITH HYPERCHOLESTEROLEMIC DIET INDUCED ATHEROCLEROSIS}

Erhan Oktay

Higher Specialized University, Turkey

BACKGROUND AND AIM: The aim of this study was to investigate the effects of plantago major extract on heart tissue oxidant/antioxidant system and some blood parameters in rabbits fed with hypercholesterolemic diet to induce atherosclerosis.

METHODS: Twenty-six male albino New Zealand rabbits were divided into five groups: The first group was assigned as Control group $(n=6)$, the second group as Cholesterol group $(n=5)$ and the remaining three groups as Plantago Major extract (PME) groups ( $\mathrm{n}=5$ in each). Saline to Control group, cholesterol $(1 \mathrm{~g} /$ $\mathrm{kg} /$ day) to Cholesterol group and PME in addition to cholesterol to the three PME groups at the doses of 0,1 (low); 0,5 (medium) and 1,0 (high) g/kg/day were administered orally for 12 weeks. Nitric oxide synthase (NOS), glutathione peroxidase (GSPx), catalase (CAT), superoxide dismutase (SOD), xanthine oxidase (XO) enzyme activities and nitric oxide (NO) and malondialdehyde (MDA) levels were measured in heart tissue samples of the animals. Triglyceride, total cholesterol and cholesterol fractions, blood urine nitrogen, creatinine, alanine and aspartate aminotransferases were also assayed in serum samples. Additionally, histopathological examination of heart tissues in each group was done.

RESULTS: As to the heart tissue NOS, GSPx, CAT, SOD, XO enzyme activities with NO and MDA levels and serum lipid parameters with liver and kidney function tests, there were no statistically significant differences between the groups other than controls. In the histological examination of heart tissue samples; connective tissue proliferation, hemorrhage and lipid vacuoles between muscle fibers were observed in cholesterol and three PME groups. There were no remarkable differences between cholesterol and PME groups compared to the histological findings.

CONCLUSIONS: In conclusion, oral administration of cholesterol alone and cholesterol plus PME were observed to have (as to the parameters measured in this study) no statistically significant effect on rabbit heart tissue oxidant / antioxidant system. Oral cholesterol administration caused some derangements in rabbit heart tissue which are evaluated to have no relation with oxidative mechanisms. Addition of PME to the diet did not exert any preventive effect against hypercholesterolemia induced derangements in the tissue.

Keywords: hypercholesterolemia, heart, oxidant/antioxidant status, plantago major, rabbit.

\section{P-055 \\ INCREASED OXIDATIVE STRESS IN CHILDREN WITH AUTISM SPECTRUM DISORDER}

Hasan Basri Savas ${ }^{1}$, Ersin Sayar ${ }^{2}$, Tayfun Kara

${ }^{1}$ Alanya Alaaddin Keykubat University, Medical Faculty, Department of Medical Biochemistry, Antalya, Turkey

${ }^{2}$ Istanbul Kanuni Sultan Suleyman Educational and Research Hospital,

Department of Pediatric Gastroenterology, Istanbul, Turkey

${ }^{3}$ Alanya Alaaddin Keykubat University, Medical Faculty, Department of Child and Adolescent Psychiatry, Antalya, Turkey

BACKGROUND AND AIM: Autism is a disorder that manifests itself with the difficulties of the child in social relations and communication in early childhood and can affect all areas of development throughout life. In our study, we aimed to investigate whether thiol disulfide balance, which is a new marker of oxidative stress, is different from normal children in children with autism spectrum disorder. METHODS: A total of 88 children, 44 with autism spectrum disorder and 44 healthy controls, were included in the study. Dynamic thiol balance, total oxidant status, total antioxidant status, ischemia modified albumin, paraoxonase 1 and arylesterase activities were measured by colorimetric methods.

RESULTS: In the experimental group with autism spectrum disorder, compared to the control group; lower levels of paraoxonase 1, total thiol and native thiol ( $p$ $<0.05$ ); higher levels of ischemia modified albumin, total oxidant state and high oxidative stress index $(\mathrm{p}<0.05)$ were determined statistically significantly.

CONCLUSIONS: There is a significant relationship between autism spectrum disorder and oxidative stress increase, antioxidant capacity decrease and dynamic thiol balance. If these data are supported by newly multi-center studies with wider participation, it can be expected that the dynamic thiol balance and other related parameters will come to the fore as laboratory markers in the etiology, diagnosis and treatment follow-up of autism. Note: This work was supported by ALKU BAP with the project numbered 202004-01-MAP03.

Keywords: Autism spectrum disorder, dynamic thiol balance, oxidative stress, antioxidant status.
P-056

MAPK SIGNALING PATHWAY AS BIOMARKER OF HYPERTENSION

Irem Mukaddes Durmus, Serdar Karakurt

Department of Biochemistry, Selcuk University, Konya, Turkey

BACKGROUND AND AIM: Hypertension adversely affects the health of many people worldwide and is fatal. Aldosterone is a hormone associated with cardiovascular disease. The most important enzyme of aldosterone biosynthesis is aldosterone synthase, and MAPK3, ERK, ELK, and LNPEP genes are also involved in aldosterone metabolism. The aim of the study is to investigate the effects of miRNAs on aldosterone metabolism, as well as to reveal the ways of use in the diagnosis and treatment of aldosterone-related diseases.

METHODS: First, a rat model of hypertension with increased aldosterone levels was created. The relationship between gene(44700 genes) and miRNA(17200 miRNA) expressions in kidney and heart tissues obtained from rat models was explained by microarray analysis and miRNA sequencing studies. Statistically significant changes were observed in 3747-transcripts in kidney tissue and 2705 -transcripts in heart tissue $(\mathrm{p}<0.05)$. Genes and miRNAs with significant level differences were selected and their gene expression was validated by qRTPCR.

RESULTS: While serum aldosterone concentration was $289.4 \mathrm{pg} / \mathrm{mL}$ before the experiment in the ALDO group, it increased to $623 \mathrm{pg} / \mathrm{mL}$ after the experiment(2.15-fold). In addition, systolic blood pressure was measured as $164 \pm 2 \mathrm{mmHg}$ in the ALDO group $(* * *<\mathrm{p} 0.0001)$. Induction of aldosterone resulted in significantly increased expression of many genes related to aldosterone biosynthesis in rat kidney tissues. In particular, mRNA expressions of LNPEP and MAPK pathway members MAPK3, ELK and ERK1/2 genes were statistically increased.

CONCLUSIONS: As a result of this study, elucidating the correlation between genes in the MAPK signaling pathway and miRNA expressions also helped to elucidate the aldosterone signaling pathway.

Keywords: Aldosterone synthesis and metabolism, Kidney-associated hypertension, MAPK signaling pathway, miRNA

\section{P-057 \\ EVALUATION OF THE EFFECT OF MESENCHYMAL STEM CELLS ON PROGRESSION OF CHRONIC RENAL DISEASE IN RATS BY ADIPONECTIN}

Ezgi Akan $^{1}$, Emre Cetindag ${ }^{2}$, Mehmet Sakinci $^{3}$, Emin Turkay Korgun $^{2}$, Dijle Kipmen Korgun

${ }^{1}$ Department of Medical Biochemistry, Akdeniz University, Turkey

${ }^{2}$ Department of Histology and Embryology, Akdeniz University, Turkey

${ }^{3}$ Department of Gynecology and Obstetrics, Akdeniz University, Turkey

BACKGROUND AND AIM: Chronic kidney disease (CKD), which can be defined as a chronic and progressive deterioration in the metabolic functions of the kidney as a result of a decrease in the glomerular filtration value, is a global disease. Current treatments are not very successful in identifying the main causes underlying the progression of renal disease. Mesenchymal stem cell (MSC) therapy offers promising results for regeneration of kidney damage. Measurable biomarkers are of great importance in demonstrating the therapeutic effects of MSCs. Adiponectin is one of the recommended biomarkers for CKD. In our study, the effect of MSCs in chronic kidney disease will be examined through adiponectin.

METHODS: In our study, firstly, mesenchymal stem cells were isolated from the amniotic membrane of human term placenta, and then the cells obtained were characterized by flow cytometry and directed to osteocytes, chondrocytes and adipocytes. In order to form the experimental groups, 5/6 nephrectomy was performed by removing the right kidney completely two weeks after the left kidneys of Wistar male rats were ligated. MSC injection was applied to the groups that underwent 5/6 nephrectomy. Protein levels of adiponectin were determined by western blot method and mRNA expressions were determined by Real-time PCR method in all groups. Urine and serum levels of adiponectin were measured by ELISA method.

RESULTS: While an increase was observed in adiponectin protein and mRNA expressions in the nephrectomy group compared to the control groups, a statistically significant decrease was determined in the stem cell injected groups after nephrectomy compared to the patient groups that were not given stem cells. In addition, a significant increase was observed in serum adiponectin levels in stem cell groups, while a significant decrease was observed in urine adiponectin levels.

CONCLUSIONS: Adiponectin, a measurable biomarker in blood and urine, has an important role in the progression of chronic kidney disease. The findings of our study may be useful for experimental and clinical studies related to MSCs in therapeutic intervention in CKD.

Keywords: Mesenchymal stem cell, chronic renal disease, adiponectin 
P-058

DETERMINATION OF REFERENCE RANGES OF SERUM

COPPER AND ZINC LEVELS IN HEALTHY INDIVIDUALS IN IZMIR BY ATOMIC ABSORPTION SPECTROPHOTOMETER AND COLORIMETRIC METHOD AND COMPARISON OF MEASUREMENT METHODS

Zeynep Hasimoglu ${ }^{1}$, Zubeyde Erbayraktar ${ }^{2}$, Serhat Erbayraktar ${ }^{3}$ ${ }^{1}$ Dokuz Eylul University Institute of Health Sciences, Department of Medical Biochemistry, Izmir, Turkey

${ }^{2}$ Special Erbayraktar Medical Center Laboratory, Izmir, Turkey

${ }^{3}$ Dokuz Eylul University Faculty of Medicine, Department of Neurosurgery, Izmir, Turkey

BACKGROUND AND AIM: Serum copper and zinc levels are very important for a strong immune system. In this study, it was aimed to determine the reference ranges of serum copper and zinc levels in healthy individuals in Izmir by atomic absorption spectrophotometer and colorimetric method and to compare the measurement methods.

METHODS: In this study, 75 healthy women and 75 men, aged 18-41 years and determined according to the inclusion criteria, were included. Serum copper and zinc levels were determined in blood samples taken by atomic absorption spectrophotometric and colorimetric methods. In the second phase of the study, method comparison experiments were performed in accordance with the "Patient Based Method Comparison Guide" of CLSI.

RESULTS: The reference range for serum copper concentrations measured in the AAS is $51.77-195.88 \mathrm{mmol} / \mathrm{L}$. The reference range for serum zinc concentrations measured in the AAS is $63.42-120.5 \mathrm{mmol} / \mathrm{L}$. The reference range for spectrophotometrically measured serum copper concentrations is 63.89-150.35 $\mathrm{mmol} / \mathrm{L}$. The reference range for spectrophotometrically measured serum zinc concentrations is $68-115.91 \mathrm{mmol} / \mathrm{L}$. Reference range for copper; it is $66-144.8$ $\mathrm{mmol} / \mathrm{L}$ in men and $64-241.2 \mathrm{mmol} / \mathrm{L}$ in women. Reference range for zinc; $60.86-$ $98.6 \mathrm{mmol} / \mathrm{L}$ in men and $54-96 \mathrm{mmol} / \mathrm{L}$ in women.

CONCLUSIONS: Reference ranges of serum copper and zinc levels in healthy individuals in Izmir were determined by both atomic absorption spectrophotometer and colorimetric method. These ranges were found to be in agreement with existing reference ranges. As a result of the comparison experiments of measurement methods, no significant difference was found

Keywords: Copper, Zinc, Reference range, Method comparison

\section{P-059 \\ DEVELOPMENT OF A RAPID AND SENSITIVE LIQUID CHROMATOGRAPHY TANDEM MASS SPECTROMETRY MEASUREMENT METHOD FOR VILDAGLIPTIN}

Ali Unlu, Duygu Eryavuz Onmaz, Abdullah Sivrikaya, Firdevs Sak, Menekse Kuzu

Selcuk University Faculty of Medicine, Department of Biochemistry, Konya,

Turkey

BACKGROUND AND AIM: Vildagliptin is an orally active and selective dipeptidyl peptidase-4 (DPP-4) inhibitor developed for the treatment of type2-diabetes. Vildagliptin, stimulate insulin secretion by preserving endogenous incretin hormones, glucagon-like-peptide-1 and glucose dependent insulinotropic polypeptide. Nasopharyngitis, headache and dizziness are the most common adverse effects associated with vildagliptin. The use of vildagliptin is associated with increased risk of pancreatitis. Plasma vildagliptin concentration should be in the range of $10-50 \mathrm{ng} / \mathrm{ml}$ for an effective treatment. The aim of this work was to develop a simple, rapid and sensitive liquid chromatography-tandem mass spectrometric (LC-MS/MS) method for quantitation of vildagliptin.

METHODS: Briefly; $250 \mu \mathrm{L}$ of sample was taken into eppendorf tubes and $100 \mu \mathrm{L}$ of internal standart and $800 \mu \mathrm{l}$ acetonitrile were added. The mixture was vortexed during 30 seconds and centrifuged at $12000 \mathrm{rpm}$ for 10 minutes. The supernatants were taken into clean glass tubes and dried under nitrogen gas at $40^{\circ} \mathrm{C}$. The dried residues were dissolved in $200 \mu \mathrm{l}$ acetonitrile:water $(10: 90, \mathrm{v} / \mathrm{v} \%)$ mixture. 30 $\mu \mathrm{L}$ was injected. Vildagliptin was detected by ABSciex API 3200 tandem mass spectrometery.

RESULTS: The developed method was linear in the concentration range of $2-1000 \mathrm{ng} / \mathrm{ml}$. The intra- and inter-assay imprecisions were less than $10 \%$. The limit of determination (LLOQ) was $2 \mathrm{ng} / \mathrm{mL}$. The mean extraction recovery was $93.4 \%$, while matrix effect values were less than $12.5 \%$. Total run time was 5 minutes.

CONCLUSIONS: A practical, economical and reliable measurement method has been developed to measure vildagliptin levels. The method may be used for routine analysis of vildagliptin.

Keywords: Therapeutic drug monitoring, mass spectrometry, vildagliptin, adverse effect.

\section{DEVELOPMENT OF LC-MS/MS METHOD FOR MEASUREMENT OF DIRECT ETHANOL BIOMARKERS ETHYL GLUCURONIDE (ETG) AND ETHYL SULFATE (ETS) IN URINE AND SERUM FOR DETECTION AND MONITORING ALCOHOL USE}

Hazal Yilmaz ${ }^{1}$, Murat Emrah Mavis ${ }^{2}$, Gokce Goksu Gursu², Oguz Polat ${ }^{1}$ ${ }^{1}$ Department of Forensic Medicine, Faculty of Medicine, Acibadem University,Istanbul, Turkey

${ }^{2}$ Sem Laboratory Devices Marketing Inc. R\&D Center, Istanbul, Turkey

BACKGROUND AND AIM: Ethyl glucuronide (EtG) and ethyl sulfate (EtS) are minor non-oxidative metabolites of ethanol. They can be detected in body fluids shortly after ethanol consumption and have a longer detection window than the parent compound. They are considered highly sensitive and specific biomarkers for recent alcohol consumption. EtG and EtS biomarkers are often used in the clinical and justice system to monitor alcohol withdrawal. In this study, it was aimed to develop an easy and cost-effective analysis methodology that provides the qualitative and quantitative detection of EtG and EtS in urine and serum matrices.

METHODS: For the simultaneous quantification of EtG and EtS biomarkers in urine and serum, an LC-MS/MS method with fast and reliable sample preparation protocols with 5 minutes analysis time has been developed and validated. Two product ions along with the precursor ions of both alcohol metabolites were monitored and the deuteron-derivative of EtG was used as an internal standard, for increasing the reliability of the results.

RESULTS: The validation parameters and obtained values were investigated based on international guidelines. They were found within acceptable ranges. Thus, sensitive determination of EtG and EtS in urine/serum samples was achieved with a simple sample preparation protocol which could be automated. CONCLUSIONS: EtG and EtS are two ethanol metabolites that can be detected in serum up to 8 hours and in urine up to 96 hours after ethanol elimination. The presence of these direct alcohol biomarkers is indicative of recent ethanol consumption in the event of a sampling delay after an event (for example, a car accident). In studies where EtG and EtS were analyzed together to determine false negative and false positive cases, it was found that false negatives and false positives in EtG results were not found in EtS results. For this reason, it is recommended to work with EtG and EtS together.

Keywords: Alcohol Biomarkers, Ethyl Glucuronide, Ethyl Sulphate, Alcohol Use Disorder, LC-ESI-MS/MS

\section{P-061}

\section{ETHYL GLUCURONIDE IN MONITORING ALCOHOL USE}

$\underline{\text { Saliha Aksun }}^{1}$, Basak Bagci ${ }^{2}$, Tugba Oncel ${ }^{1}$, Baris Karadas3, Figen Narin ${ }^{1}$, Murat Aksun ${ }^{4}$

${ }^{1}$ Izmir Katip Celebi University Medical Faculty Department of Medical Biochemistry, Izmir Katip Celebi University Atatürk Education and Research Hospital, Turkey

${ }^{2}$ Izmir Katip Celebi University Atatürk Education and Research Hospital, Psychiatry Department, Turkey

${ }^{3}$ Izmir Katip Celebi University Medical Faculty Department of Medical Pharmacology Izmir Katip Celebi University Atatürk Education and Research Hospital, Turkey

${ }^{4}$ Izmir Katip Celebi University Medical Faculty Department of Anesthesiology and Reanimation Izmir Katip Celebi University Atatürk Education and Research Hospital, Turkey

BACKGROUND AND AIM: Ethyl glucuronide (EtG) is a non-volatile, watersoluble metabolite of ethanol. It is formed as a result of enzymatic conjugation of ethanol with glucuronic acid. Etg can be detected for several days after the alcohol has been eliminated from the body. It is measured by enzyme immunoassay and chromatographic methods. It can be used together with ethanol, carbohydrate deficient transferrin (CDT), mean corpuscular volume (MCV), GGT measuremen which are other short- and long-term markers of alcohol use. The administrative threshold for EtG is $500 \mathrm{ng} / \mathrm{ml}$.

METHODS: EtG test results, which were studied with an automatic analyzer (Siemens, Dimension EXL) by immunochemical method, between January 2019 and August 2021 in the Medical Biochemistry Laboratory of İzmir Katip Celebi University Atatürk Training and Research Hospital were evaluated retrospectively.

RESULTS: Evaluation was made in 6205 urine samples. EtG mean value was found $1014(527-3546) \mathrm{ng} / \mathrm{ml}$ in 849 of these samples. Also, in 192 of patients, Disialotransferrin which is indicator of chronic alcohol use were above $2.5 \%$ $(2.5 \%-13.18 \%)$

CONCLUSIONS: In previous studies, it was reported that ethylglucuronide urine levels were remained as high in 48 hours after alcohol intake. Due to this feature, EtG can be requested to evaluate the compliance to the treatment, especially in AMATEM patients who receiving inpatient treatment for chronic alcoholism, Apart from this, Etg can be requested for people who are followed by the amatem polyclinic for their driver's license. Although it is calibrating with 500 and 1000 $\mathrm{ng} / \mathrm{ml}$ calibrators, it should not be ignored that it is a semi-quantitative test. If necessary, confirmation should be made by chromatographic method.

Keywords: alcohol, ethyl glucuronide, carbonhydrat deficient transferrin (CDT) 
P-062

QUALITATIVE AND QUANTITATIVE INVESTIGATION OF PHENOLIC SUBSTANCE COMPOSITIONS OF DRACAENA CINNABARI BALF. F. RESIN EXTRACTS OBTAINED WITH DIFFERENT SOLVENTS

$\underline{\text { Ihsan Obali }}^{1}$, Eissa Al Maghrebi ${ }^{1}$, Hakan Vatansev ${ }^{2}$, Fatma Akat $^{1}$, Husamettin Vatansev

${ }^{1}$ Institute of Health Sciences, Selcuk University, Konya, Turkey

${ }^{2}$ Department of Food Processing, Necmettin Erbakan University, Konya, Turkey

BACKGROUND AND AIM: In this study, Dracaena cinnabari Balf. f. it was aimed to determine the types of phenolic substances extracted in different solvents and their amounts.

METHODS: The substances we obtained as a result of the extraction were determined by the HPLC device of SHIMADZU (Japan-Tokyo) brand at Suleyman Demirel University YETEM-Applied Basic Sciences and Technologies Research Unit.

RESULTS: In our research, Dracaena cinnabari Balf. f. in terms of phenolic substance profiles of extracts obtained from different solvents, the most diverse 5 phenolic substances are routine $1312.5(\mathrm{mg} / \mathrm{g})$, p-hydroxy benzoic acid $1030.7(\mathrm{mg} / \mathrm{g})$, syringic acid $965.8(\mathrm{mg} / \mathrm{g})$, sinapinic acid $841.9(\mathrm{mg} / \mathrm{g})$, gallic acid $80.4(\mathrm{mg} / \mathrm{g})$ in distilled water extra fine, it was determined that grape vinegar extract has the least profile with 2 phenolic substances chlorogenic acid $15000.6(\mathrm{mg} / \mathrm{g})$, protocatechic acid $211.4(\mathrm{mg} / \mathrm{g})$. Chloroform extract with 4 phenolic substances, apigenin $40944.7(\mathrm{mg} / \mathrm{g})$, vanillin $97(\mathrm{mg} / \mathrm{g})$, p-coumaric acid $55.2(\mathrm{mg} / \mathrm{g})$, o-coumaric acid $41.2(\mathrm{mg} / \mathrm{g})$, methanol $\mathrm{In}$ the extract, 3 phenolic substances benzoic acid $909(\mathrm{mg} / \mathrm{g})$, ferulic acid $193.9(\mathrm{mg} / \mathrm{g})$, caffeic acid $167.2(\mathrm{mg} / \mathrm{g})$ were determined.In the ethanol extract, more types and amounts of substances were not found compared to other solvents.

CONCLUSIONS: In the study, benzoic acid obtained from phenolics, the highest amount of methanol extract was $909(\mathrm{mg} / \mathrm{g})$, and routine $1312.5(\mathrm{mg} / \mathrm{g})$ was determined in distilled water extract.It was determined that ethanol extract was $19921,9(\mathrm{mg} / \mathrm{g})$ and chloroform extract $40944.7(\mathrm{mg} / \mathrm{g})$ and it was the most apigenin substance among all solvents, while chlorogenic acid was $150.6(\mathrm{mg} / \mathrm{g})$ in grape vinegar extract.Undetectable substances in the extracts obtained in different solvents were determined to be quercetin, hesperidin, epicatechin, eriodictiol and catechin.

Keywords: \{Dracaena cinnabari\} Balf. f., Phenolic substance, Apigenin, Extraction, Analysis.

\section{P-063}

\section{DRACAENA CINNABARI BALF. F. TYPES OF CAROTENOID DETERMINED TO BE MOST FOUND IN EXTRACTS OF RESIN IN DIFFERENT SOLVENTS}

Husamettin Vatansev $^{1}$, Ihsan Obali ${ }^{1}$, Eissa Al Maghrebi ${ }^{1}$, Fadime Ovali ${ }^{1}$, Fatma Sengul ${ }^{2}$

${ }^{1}$ Institute of Health Sciences, Selcuk University, Konya, Turkey

${ }^{2}$ Department of Biochemistry, Adiyaman University, Konya, Turkey

BACKGROUND AND AIM: Dracaena cinnabari Balf. f. it was aimed to determine the most abundant carotenoid types and amounts of resin extracts in different solvents.

METHODS: When performing the Tocopherol analysis, Dracaena cinnabari Balf. f. $0.5 \mathrm{~g}$ of the resin samples were weighed, $20 \mathrm{ml}$ of hexane was added and left for 1 night. The hexane mixture was filtered and the filtrate was transferred to the balloon and evaporated in the evaporator. The remaining oil in the balloon was removed and analyzed in the HPLC device.

RESULTS: While there are no tocopherol substances found in higher amounts in the extracts of distilled water, chloroform and grape vinegar, which are solvents in the structure of Dracaena cinnabari Balf. f., compared to methanol and ethanol extracts, which are the other solvents used, alpha $0.23(\mu)$ is the highest amount in ethanol. $/ \mathrm{g})$, the highest amounts of delta $2.10(\mu / \mathrm{g})$, gamma $1.93(\mu / \mathrm{g})$ and beta $0.36(\mu / \mathrm{g})$ tocopherols were determined in tocopherol methanol solvent.

CONCLUSIONS: In this study, the highest Delta $2.1(\mu / \mathrm{g})$ carotene in methanol solvent, Alpha $0.23(\mu / \mathrm{g})$ carotene in ethanol solvent, alpha $0.08(\mu / \mathrm{g})$ in distilled water solvent, although not higher than other solvents. carotene, gamma $0.1(\mu / g)$ carotene in chloroform solvent and beta $0.06(\mu / \mathrm{g})$ carotene in grape vinegar solvent were determined in the highest amount. These analyzes will help to determine the active substance in future studies and to investigate the positive and negative effects of these active substances in diseases.

Keywords: \{Dracaena cinnabari\} Balf. f., Carotenoid, Delta Tocopherol, Extraction, Analysis.

\section{P-064 \\ THE EFFECT OF QUERCETIN ON METABOLIC SYNDROME COMPONENTS IN RATS FED WITH HIGH FRUCTOSES}

Kardelen Kocaman Kalkan, Belkis Narli, Canan Yilmaz Gazi University Faculty of Medicine, Department of Medical Biochemistry, Ankara, Turkey

BACKGROUND AND AIM: Metabolic syndrome (MetS) is a multi-factorial disease characterized by insulin resistance, abdominal obesity, glucose intolerance, hyperglycemia, dyslipidemia, hypertension, coronary artery disease; it causes high morbidity and mortality with its cardiac and metabolic complications. At the beginning of the treatment goals of MetS, the control of risk factors that cause insulin resistance with lifestyle changes and healthy diet come first. The aim of the study; to investigate the protective and therapeutic role of quercetin on MetS components in high fructose fed rats.

METHODS: In this direction, 24 sprague dawley type rats; were divided into 4 groups as control, fructose, quercetin, fructose+quercetin $(n=6)$. During the $10-$ week experimental period, quercetin was administered at a daily dose of $15 \mathrm{mg} / \mathrm{kg}$ via oral gavage, and fructose was administered at $20 \%$ in drinking water. Blood pressures and weights of all groups were measured and recorded. At the end of the 10th week, the animals were sacrificed under anesthesia, blood samples were taken, serum glucose, lipid profile and insulin levels were measured.

RESULTS: In our study, MetS criteria were successfully established with fructose. Positive effects were observed when quercetin was given alone and to groups with fructose, and it was revealed that it improved the MetS criteria. The results of our study suggest that $15 \mathrm{mg} / \mathrm{kg}$ quercetin administration for 10 weeks will be beneficial in lipid and carbohydrate metabolism in the fructose-mediated MetS model.

CONCLUSIONS: We believe that studies of quercetin administration at different times and doses will be useful in revealing the mechanisms in the formation of MetS components.

Keywords: Metabolic Syndrome, Fructose, Quercetin, Insulin Resistance

\section{P-065 \\ DRACAENA CINNABARI BALF. F. WITH DIFFERENT SOLVENTS PHENOLIC, ORGANIC ACID AND TOCOPHEROL SUBSTANCES DETERMINED IN MINIMUM AMOUNTS IN RESIN EXTRACT}

Eissa Al Maghrebi, Ihsan Obali, Husamettin Vatansev Institute of Health Sciences, Selcuk University, Konya, Turkey

BACKGROUND AND AIM: Dracaena cinnabari Balf.f. it was aimed to determine the types and amounts of phenolic, organic acid and tocopherol substance compositions, which were determined in minimum amounts of extracts of different solvents.

METHODS: The minimum amounts of phenolic and organic acid substances were determined with the HPLC device of SHIMADZU (Japan-Tokyo) brand of the substances included in the extractions we obtained with different solvents a Süleyman Demirel University YETEM-Applied Basic Sciences and Technologies Research Unit.

RESULTS: In this research, Dracaena cinnabari Balf. f. the first three of those determined in the minimum amounts of phenolic substance in the extracts of the resin obtained in different solvents; Syringe acid14(mg/g) in chloroform extract, o-Coumaric acid $24(\mathrm{mg} / \mathrm{g})$ ethanol extract, o-Coumaric acid $25(\mathrm{mg} / \mathrm{g})$ vinegar extract ranked from least to most.

The first three in organic acid; It was determined that ascorbic acid was 0.01 $(\mathrm{mg} / \mathrm{g})$ in methanol extract, Tartaric acid was $0.02(\mathrm{mg} / \mathrm{g})$ in methanol extract and $0.03(\mathrm{mg} / \mathrm{g})$ in ethanol extract.

Tocopherols are; Delta $0.01(\mu / \mathrm{g})$, distilled water, beta $0.02(\mu / \mathrm{g})$, chloroform, gamma $0.02(\mu / \mathrm{g})$, vinegar, alpha $0.02(\mu / \mathrm{g})$, methanol, beta $0.03(\mu / \mathrm{g})$, They were found in distilled water extract.

CONCLUSIONS: In the study, Dracaena cinnabari Balf. f. of the phenolics in the structure of the resin, the lowest amount of syringe acid is in $14(\mathrm{mg} / \mathrm{g})$ chloroform extract, organic acid, ascorbic acid is in $0.01(\mu / \mathrm{g})$ methanol extract, and Tocopherol is; Delta $0.01(\mu / \mathrm{g})$ was determined in distilled water extract. Tartaric acid was found to be higher in the same solvent than Ascorbic acid in methanol solvent, which is one of the organic acids. The amount of tartaric acid varies in different solvents. While tocopherols delta and beta carotenoids were determined in different amounts in the same solvent, distilled water solvent, it was observed that beta carotenoid amounts were different in distilled water chloroform solvent, which is different solvents.

This shows us that the solvents of each substance are different, and that even the same solvent dissolves different substances in different amounts. When it is desired to use trace amounts of these and similar substances in all medical researches, these analyzes will speed up the studies Keywords: \{Dracaena cinnabari\} Balf. f., Phenolic substance, Organic asid, Carotenoid, Extraction, Analysis. 


\section{P-066 \\ THE EFFECT OF VITAMINE D DEFICIENCY ON THE RELEASE OF GHRELINE AND LEPTIN HORMONE IN RABBITS}

Emine Atakisi, Cafer Ozturk, Serpil Aygormez

Kafkas University Faculty of Veterinary Medicine Department of Biochemistry, Kars, Turkey

BACKGROUND AND AIM: Vitamin D differently from other vitamins is synthesized in the body and is therefore regarded as a hormone. A body that has vitamin $\mathrm{D}$ up to its merit sends a leptin hormone that gives the brain a feeling of satiety. In this context, low vitamin D means less leptin and more hunger. Fat cells are endocrinologically active cells and contain vitamin D receptor. Thus, fat tissue is among the target tissues for active vitamin D. The aim of this study is to investigate the effect of leptin and ghrelin hormone levels in rabbits with deficient D vitamins.

METHODS: The study was carried out on 16 New Zealand rabbits. Following the 15-day adaptation period, feed and drinking water were given as ad libitum to the groups formed as 8 rabbits each. Group I rabbits were fed with normal pellet feed and group II rabbits for 24 weeks with D vitamin deficient.

RESULTS: Serum leptin, ghrelin and vitamin D levels were determined by ELISA with commercial kits. Serum D vitamine level was significantly lower $(\mathrm{p}<0.005)$ in the group lacking vitamin $\mathrm{D}$ than the other group. Serum ghrelin and leptin levels were significantly lower $(\mathrm{p}<0.05)$ in the D group than in the other group.

CONCLUSIONS: In rabbits, it was determined that $\mathrm{D}$ vitamins should be fed for at least 6 months with feed added to form vitamin D deficiency, rabbit D vitamine deficiency lowered levels of lipid metabolism and energy balance, leptin and ghrelin hormones related to nutrient intake appetite mechanisms.

Keywords: Vitamine D deficiency, Ghrelin, Leptin, Rabbit

\section{P-067 \\ THE EFFECT OF WET CUPPING THERAPY ON THE KYNURENINE PATHWAY}

Fatma Humeyra Yerlikaya ${ }^{1}$, Duygu Eryavuz Onmaz ${ }^{1}$, Berivan Unat ${ }^{2}$ Hayriye $\mathrm{Alp}^{3}$, Gulsum Abusoglu ${ }^{4}$, Ali Unlu ${ }^{1}$

${ }^{1}$ Selcuk University Faculty of Medicine, Department of Biochemistry, Konya Turkey

${ }^{2}$ Necmettin Erbakan University, Meram Faculty of Medicine, Department of Biochemistry, Konya, Turkey

${ }^{3}$ Necmettin Erbakan University, Meram Faculty of Medicine, Department of Traditional and Complementary Medicine, Konya, Turkey

${ }^{4}$ Selcuk University Vocational School of Health, Department of Medical

Laboratory Techniques, Konya, Turkey

BACKGROUND AND AIM: Wet cupping theraphy (WCT) is commonly used in different conditions such as hypertension, diabetes, inflammatory diseases. The mechanism of action of wet cupping therapy is not yet clear, however several studies have demonstrated that it has a role in limiting oxidative stress and inflammation. The tryptophan kynurenine pathway plays a key role in inflammation and immune response. The aim of the study is to contribute to the elucidation of the mechanism of action of WCT in inflammation by measuring tryptophan and kynurenine levels in wet cupping and venous blood samples taken concurrently from subjects who underwent WCT.

METHODS: WCT was implemented to 50 volunteer women. Venous blood and wet cupping blood samples were taken concurrently. Venous blood and wet cupping blood samples tryptophan and kynurenine levels were measured using a validated tandem mass spectrometric method through a pretreatment procedure requiring protein precipitation with acetonitrile.

RESULTS: Serum tryptophan [4658 (857-12100) ng/ml vs 2955 (517-5160) ng/ $\mathrm{ml}, \mathrm{p}=0.003$ ], kynurenine levels [376.5 (61-850) ng/ml vs $235.8(57-695) \mathrm{ng} / \mathrm{ml}$, $\mathrm{p}<0.001]$ and Kynurenine/Tryptophan [0.0891 (0.04-0.41) vs $0.0752(0.02-0.17)$, $\mathrm{p}=0.041]$ ratio were statistically significantly higher in wet cupping samples compared to venous blood. The inter-assay $\mathrm{CV} \%$ values for all analytes were less than $11.2 \%$ of the tandem mass spectrometric method used in the quantitation of analytes. Recovery\% values ranged from $93.1 \%$ to $107.8 \%$ for all analytes, while the matrix effect values were less than $10 \%$.

CONCLUSIONS: Our findings suggest that WCT contributes to the reduction of the Kynurenine/Tryptophan ratios. Therefore, our study supports the finding that WCT may be beneficial especially in the prevention of inflammatory chronic diseases.

Keywords: Wet cupping theraphy, inflammatory diseases, kynurenine, tryptophan.

\section{P-068 \\ DETERMINATION OF SERUM FATTY ACIDS BY GAS CHROMATOGRAPHY MASS SPECTROMETRY}

Duygu Eryavuz Onmaz ${ }^{1}$, Abdullah Sivrikaya ${ }^{1}$, Mustafa Topkafa ${ }^{2}$, Oguzhan Tok $^{1}$, Aysenur Kose ${ }^{1}$, Mohammad Ahmad Bik ${ }^{1}$

'Department of Biochemistry, Selcuk University Faculty of Medicine, 42130, Konya, Turkey

${ }^{2}$ Konya Technical University, Vocational School of Technical Sciences,

Department of Chemistry and Chemical Processing Technologies 42250 Konya, Turkey

BACKGROUND AND AIM: Fatty acids (FA) are amphipathic compounds consisting of a non-polar hydrocarbon chain and polar carboxylic acid group. It is known that FA play an important role in cell homeostasis, affect the immune system, and have antimicrobial and anticancer activity. The aim of this study is to develop a simple, fast and accurate gas chromatography-mass spectrometry (GC-MS) method for the detection and quantification of FA.

METHODS: $100 \mu \mathrm{l}$ of internal standard (Methyl heptadecanoate), $50 \mu \mathrm{l}$ of serum and $1 \mathrm{ml}$ of freshly prepared $3 \mathrm{~N}$ methanolic $\mathrm{HCl}$ were added to a $4 \mathrm{ml}$ glass tube. It was incubated at $90^{\circ} \mathrm{C}$ for 4 hours to achieve transmethylation. After the tubes were cooled to room temperature, $2 \mathrm{ml}$ of hexane was added and vortexed for 10 seconds. The supernatant was transferred to a glass tube and evaporated under nitrogen gas at room temperature. The residues in the tubes were dissolved with $100 \mu 1$ of hexane and injected into the GC-MS system.

RESULTS: Developed method C11:0, C13:0, C15:0, C16:1, C17:0, C17:1, C18:1 $\omega 9 t, \mathrm{C} 18: 2 \omega 6 \mathrm{t}, \mathrm{C} 18: 2 \omega 6 \mathrm{c}, \mathrm{C} 21: 0, \mathrm{C} 20: 2, \mathrm{C} 20: 3 \omega 6, \mathrm{C} 22: 1 \omega 9, \mathrm{C} 20: 3 \omega 3, \mathrm{C} 20: 4$ $\omega 6, \mathrm{C} 23: 0, \mathrm{C} 22: 2, \mathrm{C} 24: 1, \mathrm{C} 20: 5 \omega 3, \mathrm{C} 20: 6 \omega 3, \mathrm{C} 10: 0, \mathrm{C} 12: 0, \mathrm{C} 14: 0, \mathrm{C} 18: 0$ $\mathrm{C} 18: 1 \omega 9 \mathrm{c}, \mathrm{C} 20: 0, \mathrm{C} 22: 0, \mathrm{C} 24: 0, \mathrm{C} 16: 0$ It was linear in the range of 6.25 to 300 $\mu \mathrm{g} / \mathrm{ml}$ for Total analysis time was approximately 65 minutes for one sample. CONCLUSIONS: As a result of our study, a multiplex analysis method was developed that allows the analysis of serum levels of FA in a common method with the same pretreatment steps.

Keywords: Fatty acids, gas chromatography, mass spectrometry, bioanalysis

\section{P-069 DETERMINING THE SHELF LIFE OF A NEW DESIGNED UREA BIOSENSOR}

Erkan Oguz ${ }^{1}$, Mehmet Akif Curuk ${ }^{2}$

${ }^{1}$ Mersin University, Department of Pharmacy Biochemistry, Mersin

${ }^{2}$ Department of Microbiology, Medical Faculty, Cukurova University, Adana, Turkey

BACKGROUND AND AIM: Urea is a harmful substance to the human body, which is formed as a result of the use and breakdown of protein foods. This substance is discharged by the kidneys and excreted in the urine. If the kidneys cannot excrete this substance enough, it starts to accumulate in the blood. Its elevation has a toxic effect on the body, and when it is too high, it is impossible to live. For these reasons, urea determination is of great medical importance.

METHODS: In this study, we aimed to design a new amperometric biosensor for urea determination. For the determination of urea, the urease enzyme was immobilized on the graphite electrode by using BSA/Gelatin and cross-linking with glutaraldehyde. Measurements were carried out at $0.2 \mathrm{~V}$. Optimization studies of the designed biosensor were carried out to determine the bioactive layer components and shelf life.

RESULTS: From bioactive layer optimization studies; Gelatin, bovine serum albumin content and optimal glutaraldehyde percentage were determined as $0.45 \mathrm{~g}, 0.030 \mathrm{~g}$ and $2.5 \%$ for the graphite/BSA-Gelatin/Urease/glutaraldehyde modified biosensor. When we look at the shelf life studies, it was found that the results were preserved at the rate of $82.5 \%$ at the end of the 40 th day.

CONCLUSIONS: When we look at the shelf life studies, it was found that the results were preserved at the rate of $82.5 \%$ at the end of the 40th day.

Keywords: Biosensor, Urea, Urease

\section{P-070 \\ EXAMPLE OF MEASUREMENT UNCERTAINTY IN CALCULATED TESTS: CALCULATED PLASMA OSMOLALITY}

Semih Fazli Kayahan, Yunus Emre Haskilic, Gizem Yilmaz Calik, Fatih Serin, Hacer Dogan, Mehmet Senes

Ankara Training and Research Hospital, Department of Medical Biochemistry, Ankara, Turkey

BACKGROUND AND AIM: Plasma osmolality can be measured as well as calculated using glucose, urea and sodium test results. Our aim in this study is to determine the measurement uncertainty of calculated osmolality in our own laboratory.

METHODS: Measurement uncertainties of sodium, urea and glucose performed on Roche Cobas 8000 autoanalyzer were calculated.Then, using these data, the measurement uncertainty for 'Calculated Osmolality' was calculated. Measurement uncertainty calculations were made according to the ISO/TS 20914 
measurement uncertainty guideline using the formula $(\mathrm{u}(\mathrm{y})=\mathrm{urw}+\mathrm{ucal}) *(\mathrm{Urw}$ : intermediate precision conditions of measurement, Ucal: calibrator uncertainty). Two levels of internal quality control data studied between 15.02.2021 and 06.09.2021 were used for the Urw calculation. The uncertainty calculation for both levels was done separately.Within the scope of ISO/TS 20914 guideline, the SD of internal quality control data was accepted as uRw.Ucal data was obtained from Roche Diagnostics. The expanded uncertainty of measurement [U(y)] was obtained by multiplying the result $\mathrm{u}(\mathrm{y})$ with the coverage factor $(\mathrm{k})(\mathrm{k}=2)$. Thepercentrelativeuncertainty ofmeasurement (\%Urel)ofthemeasuredparameters was calculated with the formula (U(y)/internal quality control mean)*100. Osmolality percent relative uncertainty of measurement (\%Urel) was calculated with the formula $(\mathrm{U}(\mathrm{y}) / \mathrm{osmolality}$ result $) * 100$. U(calculated osmolality $)=$ $\sqrt{(}\left(2^{2} \mathrm{xu}^{2}(\right.$ sodium $)+\mathrm{u}^{2}($ urea $)+\mathrm{u}^{2}($ glucose $\left.)\right)$ was calculated. The level of uncertainty to be used in the parameters was decided by looking at the midpoint of the mean values of the controls.

RESULTS: The low-level combined standard uncertainty for sodium, urea, and glucose were $1.57,0.05,0.14$ and the high-level combined standard uncertainty of thesemeasurements were $1.58,0.35$, and 0.30 respectively. Fora sample with Na: 135 $\mathrm{mmol} / \mathrm{L}$, Urea: $9 \mathrm{mmol} / \mathrm{L}$, Glucose: $7 \mathrm{mmol} / \mathrm{L}$, plasma osmolality $=295 \mathrm{mOsmol} / \mathrm{L}$. Level 2 control uncertainty for $135 \mathrm{mmol} / \mathrm{L}$ sodium, level 2 control uncertainty for $9 \mathrm{mmol} / \mathrm{L}$ urea, and level 1 control uncertainty for $7 \mathrm{mmol} / \mathrm{L}$ glucose were taken into account in the calculation of uncertainty for the calculated osmolality. The uncertainty of the calculated osmolality test accordingly u(osmolality) $=3.17$; $\mathrm{U}($ osmolality $)=6.35 ;$ It was calculated as $\%$ Urel $($ osmolality $)=(U($ osmolality $) / 295)$ $\mathrm{x} 100=2.15$.

CONCLUSIONS: The calculation of measurement uncertainties by clinical biochemistry laboratories improves the clinician's contribution to patient management. At this point, it is important to calculate the measurement uncertainty of not only the measured parameters but also the calculated parameters. Keywords: calculated, measurement uncertainty, osmolality

\section{P-071}

PRE-ANALYTICAL STABILITY FOR FREQUENTLY RERUN ROUTINE IMMUNOASSAY TESTS = A SMALL-SCALE LABORATORY EXPERIENCE

\section{Burak Arslan}

Van Ercis State Hospital, Biochemistry Laboratory, Van, Turkey

BACKGROUND AND AIM: Sample handling prior to analysis has the potential to dramatically affect the results of a measurement. Thus, it has utmost importance to investigate if different storage conditions contribute to systematic errors in order to provide the clinicians with adequate sample collection and transport instructions.On the top of that, pre-analytical variation can occur during collection,processing and storage of the blood and could result in non-biological variation of measurement levels.Herein, my aim was to assess the storage and freeze/thaw (f/t) stability of free triiodothyronine(FT3), thyroxine (FT4) and thyroid stimulating hormone (TSH).

METHODS: Firstly I have specified immunoassay tests, which were pended or processed for re-run mostly in my laboratory, respectively(TSH, FT4, FT3).It were repeated the following steps for three independent samples each analyte with different concentrations of the measurand(low, medium, high(L,M,H)). 10 $\mathrm{mL}$ serum pool was prepared for each analyte $(\mathrm{L}, \mathrm{M}, \mathrm{H})$. The concentrations of each serum pool at $\mathrm{t}=0$ point were measured.Samples are divided into nineteen aliquots with equal sample volume $(500 \mu 1)$.Aliquotes experimentally exposed to delayed storage: $0,1,2,4,24,72$, or $168 \mathrm{~h}$ at $4{ }^{\circ} \mathrm{C}$ or room temperature(RT), or $1-4$ months at $-20^{\circ} \mathrm{C}$; or up to $7 \mathrm{f} / \mathrm{t}$ cycles, before final storage at $-20^{\circ} \mathrm{C}$. All aliquots have been thawed for a given sample simultaneously and analyzed them in duplicates in the same run.Raw data of aliquots(replicates of observed concentrations) were recorded Excel File (Microsoft Excel for Mac).Thanks to the designed excel, file calculates the mean value,SD and coefficient of variation $(\% \mathrm{CV})$ for both the observed concentration and normalized concentration. The SD for the storage conditions and the freeze/thaw aliquots must be within the acceptance criteria for the precision defined in the fit-for-purpose.

RESULTS: For $\mathrm{f} / \mathrm{t}$ stability evaluation, the highest change for $\mathrm{TSH}$ was observed at the $\mathrm{M}$ levels introduced into the $\mathrm{f} / \mathrm{t}$ cycle 5 times (Mean Normalized Concentration $81.4 \%$, SD Normalized Concentration 6.15, CV Normalized Concentration $7.55 \%$ ). For storage stability evaluation, the highest change was observed at L level of FT3 kept at 72H RT (Mean Normalized Concentration \% 87.3, SD Normalized Concentration 2.86, \%CV Normalized Concentration 3.28). CONCLUSIONS: In conclusion, levels of thyroid function tests appeared resistant to common experimental storage and freeze/thaw conditions.

Keywords: Stability, Freeze, Thaw, Thyroid function tests
P-073

OPINIONS OF HIGH SCHOOL STUDENTS ON VACCINE REJECTION

Nurcan Evliyaoglu

Department of Medical Biochemistry,Secuk University, Konya, Turkey

BACKGROUND AND AIM: By vaccination, individual immunity is provided and the person is protected from the disease, while at the same time socia immunity is provided. This study aims to determine the views of high school students on vaccine rejection.

METHODS: In the study, 130 high school students were reached.In data collection 12-question survey form developed based on literature knowledge was applied. RESULTS: $60 \%$ of the participants in the study are girls and $40 \%$ are boys. Average age is $15.28 .75 \%$ of the participants think that if the vaccine rejection becomes widespread in the society, the public health will be adversely affected, who states that reading-hearing negative things about vaccines and negative statements about vaccines by people who are accepted as role-models in the society may cause this situation.

CONCLUSIONS: High school students think that with the increase in vaccine rejection, epidemics in the society will increase, and they stated that scientific research should be done to prevent this. With the increase of students' knowledge and awareness about vaccine rejection, it will be possible to raise generations sensitive to social immunity.

Keywords: Vaccine Rejection, Epidemic, Immunity

\section{P-074}

\section{FALSE ELEVATION OF BETA-HUMAN CHORIONIC} GONADOTROPIN IN IMMUNOGLOBIN A DEFICIENCY

Mert Andac Temel, Ebru D. Sezer

Ege University Faculty of Medicine, Department of Medical Biochemistry, Izmir, Turkey

BACKGROUND AND AIM: Human chorionic gonadotropin hormone ( $\beta$-hCG is essential in the diagnosis and follow-up of pregnancy, molar pregnancy, and various malignancies. It is known that the false elevation of this parameter can cause false cancer diagnosis in both men and women and unnecessary chemotherapy. One of the important causes of false $\beta$-hCG elevation is $\operatorname{IgA}$ deficiency in which heterophile antibodies develop. The aim of this study is to retrospectively investigate whether false $\beta$-hCG elevation is observed in patients with Ig-A deficiency in Ege University Medical Faculty (EUTF) Hospital.

METHODS: $\beta$-hCG levels of 4612 patients with IgA deficiency $(<0.27 \mathrm{~g} / \mathrm{L})$ who applied to EUTF Hospital between 2019-2021 were screened retrospectively. IgA levels were studied by nephelometric method (SIEMENS BN2), and $\beta$-hCG levels were measured by sandwich electrochemiluminescence method (COBAS6000). RESULTS: $\beta$-hCG levels were also requested by the clinicians and measured in 22 of 4612 individuals with IgA deficiency. In 6 of them, an increase in $\beta$-hCG (> $0.1 \mathrm{U} / \mathrm{L}$ ) was detected, but in 5 of these cases the situation could not be explained clinically and further investigation was not conducted. In the remaining one patient, recurrent $\beta$-hCG measurements continued to be elevated and bilateral salpingooopherectomy was applied to the patient.

CONCLUSIONS: IgA Deficiency is the most common cause of primary-immune deficiency in Europe(1/223-1/1000). In these patients heterophile-antibodies are formed for unexplained reasons and may interfere with electrochemiluminescence, most commonly with the immunometric sandwich method, and cause false elevated $\beta$-hCG results. With results of the retrospective scan in patients with IgA deficiency and elevated $\beta-h C G$, it is questionable if the elevation of $\beta-h C G$ may be due to interference, since no further studies have been conducted for the presence of heterophile antibodies in the blood or the determination of $\beta$-hCG in the urine. Since heterophile antibodies do not pass into the urine, a simple parallel measurement of $\beta-h C G$ in the urine in every suspected case of this type will prevent misdiagnosis treatment and unnecessary medical interventions.

Keywords: Ig A deficiency, beta human chorionic gonadotropin, heterophile antibodies, interferance 